\title{
The Vesicular GABA Transporter, VGAT, Localizes to Synaptic Vesicles in Sets of Glycinergic as Well as GABAergic Neurons
}

\author{
Farrukh A. Chaudhry, ${ }^{1,2}$ Richard J. Reimer, ${ }^{2}$ Elizabeth E. Bellocchio, ${ }^{2}$ Niels C. Danbolt, ${ }^{1}$ Kirsten K. Osen, ${ }^{1}$ \\ Robert H. Edwards, ${ }^{2}$ and Jon Storm-Mathisen ${ }^{1}$ \\ ${ }^{1}$ Department of Anatomy, Institute of Basic Medical Sciences, University of Oslo, N-0317 Oslo, Norway, and \\ 2Departments of Neurology and Physiology, University of California San Francisco School of Medicine, San Francisco, \\ California 94143-0435
}

\begin{abstract}
A transporter thought to mediate accumulation of GABA into synaptic vesicles has recently been cloned (Mclntire et al., 1997). This vesicular GABA transporter (VGAT), the first vesicular amino acid transporter to be molecularly identified, differs in structure from previously cloned vesicular neurotransmitter transporters and defines a novel gene family. Here we use antibodies specific for $\mathrm{N}$ - and C-terminal epitopes of VGAT to localize the protein in the rat CNS. VGAT is highly concentrated in the nerve endings of GABAergic neurons in the brain and spinal cord but also in glycinergic nerve endings. In contrast, hippocampal mossy fiber boutons, which although glutamatergic are known to contain GABA, lack VGAT immunoreactivity. Post-embedding immunogold quantification shows that the
\end{abstract}

Neurotransmitters are taken up and stored in synaptic vesicles before exocytotic release to the synaptic cleft (Liu and Edwards, 1997). Synaptic vesicle preparations express several distinct neurotransmitter transport activities, and molecular cloning has identified cDNAs encoding vesicular transporters for monoamines (VMAT1 and VMAT2) and acetylcholine (VAChT) (Erickson et al., 1992, 1994; Liu et al., 1992). However, the vesicular transport of amino acid transmitters differs in mechanism from the transport of monoamines and acetylcholine. In contrast to the VMATs and VAChT, which rely chiefly on the $\mathrm{pH}$ gradient $(\Delta \mathrm{pH})$ across the vesicle membrane to drive active transport, vesicular glutamate transport depends almost entirely on the electrical gradient $(\Delta \psi)$, vesicular GABA transport depends equally on $\Delta \psi$ and $\Delta \mathrm{pH}$, and vesicular glycine transport resembles vesicular GABA transport in the bioenergetic mechanism (Fykse and Fonnum, 1988, 1996; Maycox et al., 1990). However, competition studies using synaptic vesicles from different brain regions have not definitively resolved whether a single transporter packages both GABA and glycine or distinct proteins package the two transmitters (Kish et al., 1989; Christensen et al., 1990, 1991; Burger et al., 1991). Although in the forebrain most inhibitory nerve endings have high concentrations of GABA but not glycine,

Received May 26, 1998; revised Sept. 21, 1998; accepted Sept. 22, 1998.

This work was supported by the Norwegian Research Council, Fylkesakers Stiftelse, Langfeldts Fond, and Nansenfondet (F.A.C. and J.S.-M.) and by the National Institute of Mental Health and National Institute of Neurological Diseases and Stroke (R.H.E. and R.J.R.). We are gratef ul to Edward Fon, Even Andersen, Carina Knutsen, Gunnar F. Lothe, and Håvard Tønnesen for technical assistance and to Jan G. Bjaalie for making available the methods for analyzing particle-vesicle distances. Correspondence should be addressed to Jon Storm-Mathisen, Anatomical Institute, University of Oslo, P.O. Box 1105 Blindern, N-0317 Oslo, Norway. E-mail: jonsm@pons.uio.no

Copyright (C) 1998 Society for Neuroscience $\quad 0270-6474 / 98 / 189733-18 \$ 05.00 / 0$ protein specifically associates with synaptic vesicles. Triple labeling for VGAT, GABA, and glycine in the lateral oliva superior revealed a higher expression of VGAT in nerve endings rich in GABA, with or without glycine, than in others rich in glycine only. Although the great majority of nerve terminals containing GABA or glycine are immunopositive for VGAT, subpopulations of nerve endings rich in GABA or glycine appear to lack the protein. Additional vesicular transporters or alternative modes of release may therefore contribute to the inhibitory neurotransmission mediated by these two amino acids.

Key words: neurotransmitter transport; synaptic vesicles; GABA; glycine; antibodies; immunogold; microscopy in the spinal cord and brainstem nerve endings colocalize GABA and glycine and at many sites are more abundant than nerve endings rich in only one of the two inhibitory amino acids (Ottersen et al., 1988, 1995; Helfert et al., 1989, 1992; Osen et al., 1990; Ottersen and Storm-Mathisen, 1990; Todd and Sullivan, 1990; Kolston et al., 1992; Wentzel et al., 1993; Örnung et al., 1994, 1996, 1998; Taal and Holstege, 1994; Juiz et al., 1996; Lahjouji et al., 1996; Yang et al., 1997).

Genetic and pharmacological studies in Caenorhabditis elegans have recently led to the identification of the first vesicular transporter for an amino acid (McIntire et al., 1997). The mutant unc-47 appears to have a presynaptic defect in GABAergic transmission and, surprisingly, accumulates large amounts of GABA. Complementation studies identified the affected gene, which encodes a polytopic membrane protein, suggesting a role in vesicular GABA transport. Supporting this possibility, expression of the gene and its mammalian homolog in heterologous cell systems conferred vesicular GABA transport with the anticipated dependence on both $\Delta \psi$ and $\Delta \mathrm{pH}$. This vesicular GABA transporter (VGAT) was competitively inhibited by glycine but with low potency $\left(\mathrm{IC}_{50} 25 \mathrm{~mm}\right)$ and did not show significant transport of $\left[{ }^{3} \mathrm{H}\right]$ glycine, raising the possibility of a distinct vesicular transporter for glycine but not excluding a role for VGAT in glycine packaging. In $C$. elegans the protein is selectively expressed in all of the nematode's GABAergic neurons, and in rat the distribution of VGAT mRNA also indicates expression in GABAergic neurons.

Here we use antibodies that specifically recognize VGAT to investigate the regional, cellular, and subcellular localization of the transport protein in rat brain. By electron microscopic postembedding immunogold quantification, VGAT appears at high 
levels in glycinergic as well as GABAergic nerve endings and associates with synaptic vesicles. A subpopulation of boutons rich in GABA and/or glycine seems to lack VGAT.

\section{MATERIALS AND METHODS}

$N$-terminal fusion protein. A DNA fragment corresponding to the N-terminal 99 amino acids of VGAT was amplified by PCR from the rat cDNA using Pfu polymerase (Stratagene, La Jolla, CA) and the primers 5'-CGGGATCCCATGGCCACCCTGCTCCGC-3' and 5'-GGGAATTCGTCCTTGGAGCCCGAGGG-3'. After digestion with BamHI and EcoRI (Life Technologies, Gaithersburg, MD), the PCR product was inserted in-frame into the glutathione $S$-transferase (GST) vector PGEX-3X (Pharmacia Biotech, Piscataway, NJ) using T4 DNA ligase (Life Technologies). The construct was then sequenced to confirm the absence of unwanted mutations in the PCR-generated fragment.

To produce the GST-VGAT fusion protein, Escherichia coli transformed with the construct were grown overnight at $37^{\circ} \mathrm{C}$ in $1.6 \%$ tryptone, induced with $100 \mu \mathrm{M}$ isopropyl $\beta$-D-thiogalactoside for an additional 3-6 hr at room temperature, pelleted, resuspended in PBS, and disrupted by vigorous sonication at $0^{\circ} \mathrm{C}$. The lysate was sedimented at $14,000 \times g$ to remove cell debris, and the cleared extract was incubated with glutathione-Sepharose beads (1 hr at room temperature in PBS). After washing three times with PBS, the GST fusion protein was eluted from the beads with $10 \mathrm{~mm}$ glutathione and $50 \mathrm{~mm}$ Tris-HCl, $\mathrm{pH} 8.0$.

Coupling of synthetic peptide to carrier protein. A peptide corresponding to the C-terminal 17 amino acids of VGAT was synthesized with an additional N-terminal cysteine (CVHSLEGLIEAYRTNAED) and coupled to the carrier protein keyhole limpet hemocyanin $(\mathrm{KLH})$ through the N-terminal cysteine using $m$-maleimidobenzoyl- $N$-hydroxysuccinimide ester.

Immunization. The GSH-VGAT fusion protein $(300 \mu \mathrm{g})$ and $\mathrm{KLH}-$ conjugated peptide $(200 \mu \mathrm{g})$, prepared as described above, were diluted in $500 \mu \mathrm{l}$ of PBS, emulsified with $500 \mu \mathrm{l}$ of Freund's complete adjuvant (Life Technologies), and injected intradermally into 14-week-old female New Zealand White rabbits. After 1 month, the animals were boosted

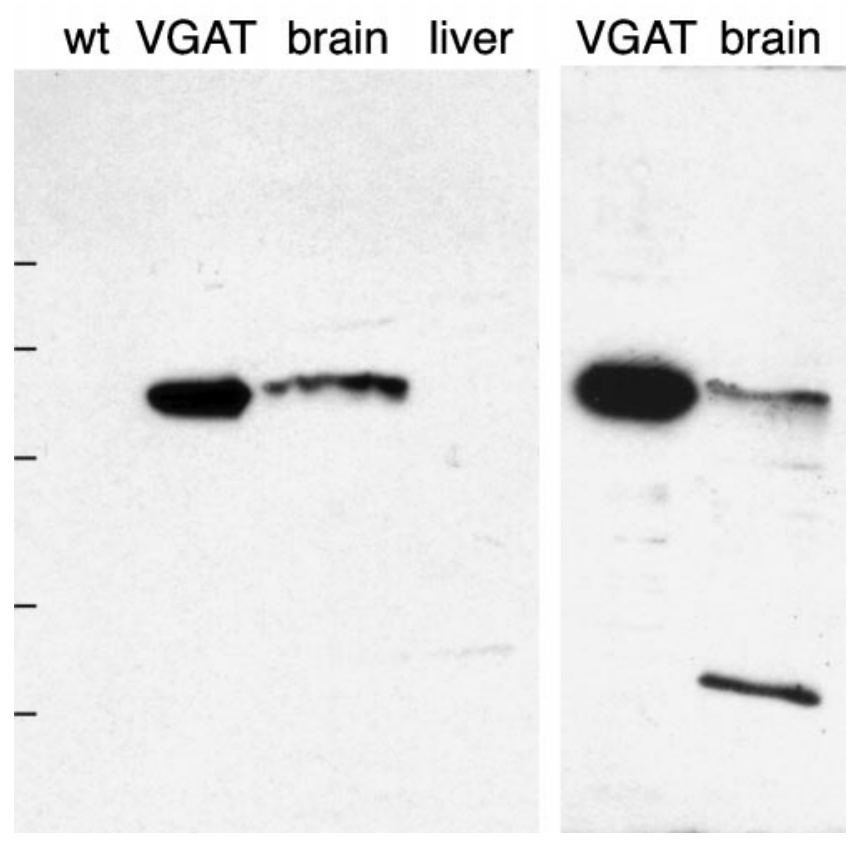

Figure 1. Specificity of antibodies to VGAT as demonstrated by immunoblotting after electrophoretic (SDS-PAGE) separation of proteins. Left, N2 antibody. Right, C1 antibody. Extracts of brain and VGATexpressing PC12 cells (VGAT) show bands with a similar molecular mass $(\sim 57 \mathrm{kDa})$. The bands are absent in liver and wild-type PC12 cells $(w t)$. Positions of molecular mass standards are indicated on the left $(83,62$, $47.5,32.5$, and $25 \mathrm{kDa}$, consecutively from the top).
Figure 2. Regional localization of VGAT shown by immunoperoxidase staining (with Triton) of closely spaced parasagittal Vibratome sections of rat brain. Antibodies $\mathrm{N} 2$ to the $\mathrm{N}$-terminal fusion protein $(A)$ and $\mathrm{C} 1$ to the $\mathrm{C}$-terminal peptide $(B)$ show the same distribution of immunoreactivity. Strong staining is shown in recognized targets of GABAergic nerve terminals (see Results). $A$, Amygdaloid nuclei; $A D$ area dentata; $A H i$, amygdalohippocampal area; $C A 1, C A 3$, hippocampal subfields; $C b x$, cortex cerebellaris; $C I$, colliculus inferior; $C S$ colliculus superior; $C x$, cortex cerebralis; $C e$, central cerebellar nuclei (nucleus interpositus); $C P$, caudatoputamen; $D C$, dorsal nucleus cochlearis; $E P$, nucleus entopeduncularis; GP, globus pallidus; $L O T$, nucleus tractus olfactorius lateralis; $N 7$, nucleus facialis; $S N R$, substantia nigra pars reticulata; $R t$, nucleus reticularis thalami; Pir, cortex piriformis; $T h$, thalamic nuclei; $S p 5$, nucleus tractus spinalis nervi trigemini; $T u$, tuberculum olfactorium; $V e$, vestibular nuclei; $V P$, ventral pallidum; $Z I$, zona incerta. Scale bar, $2 \mathrm{~mm}$.
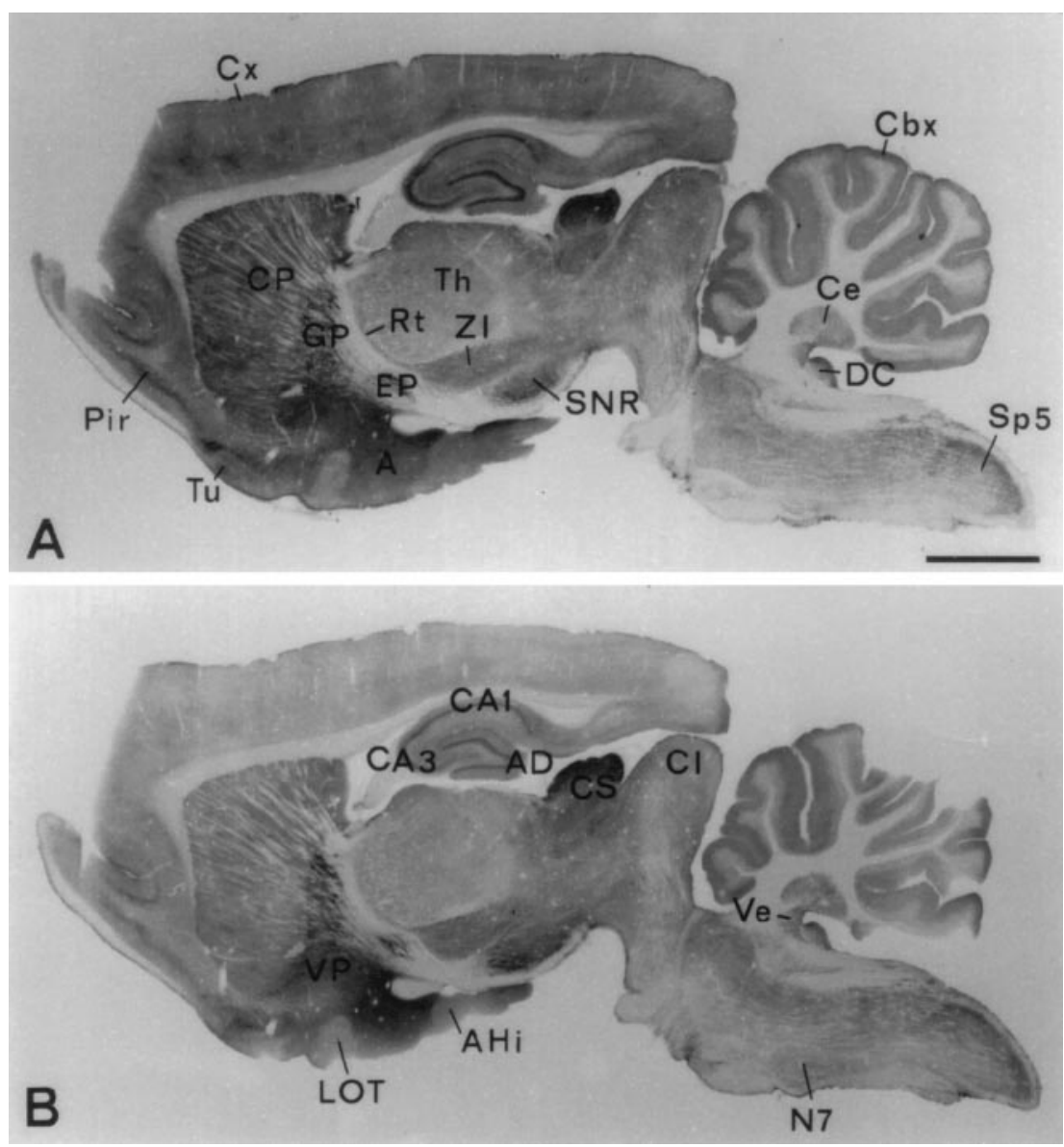


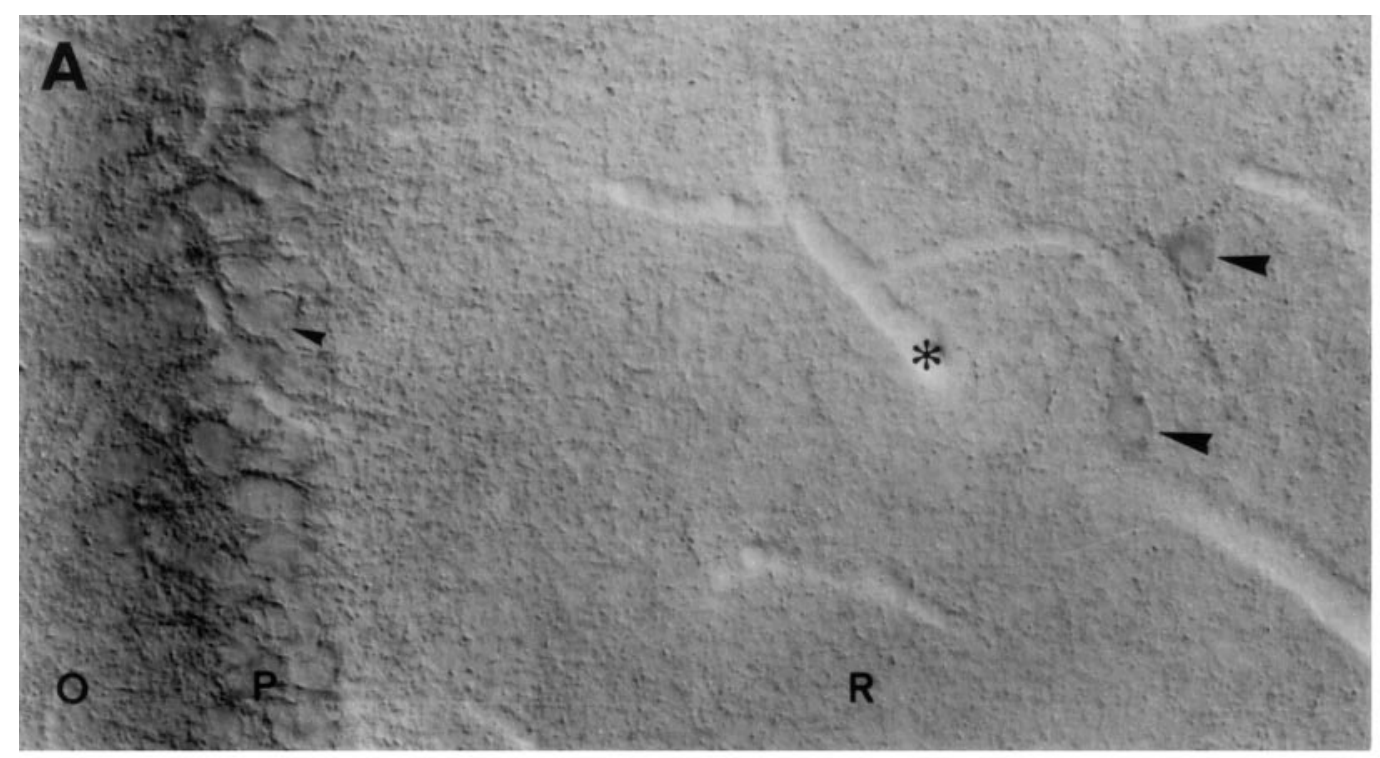

$\mathbf{P}$
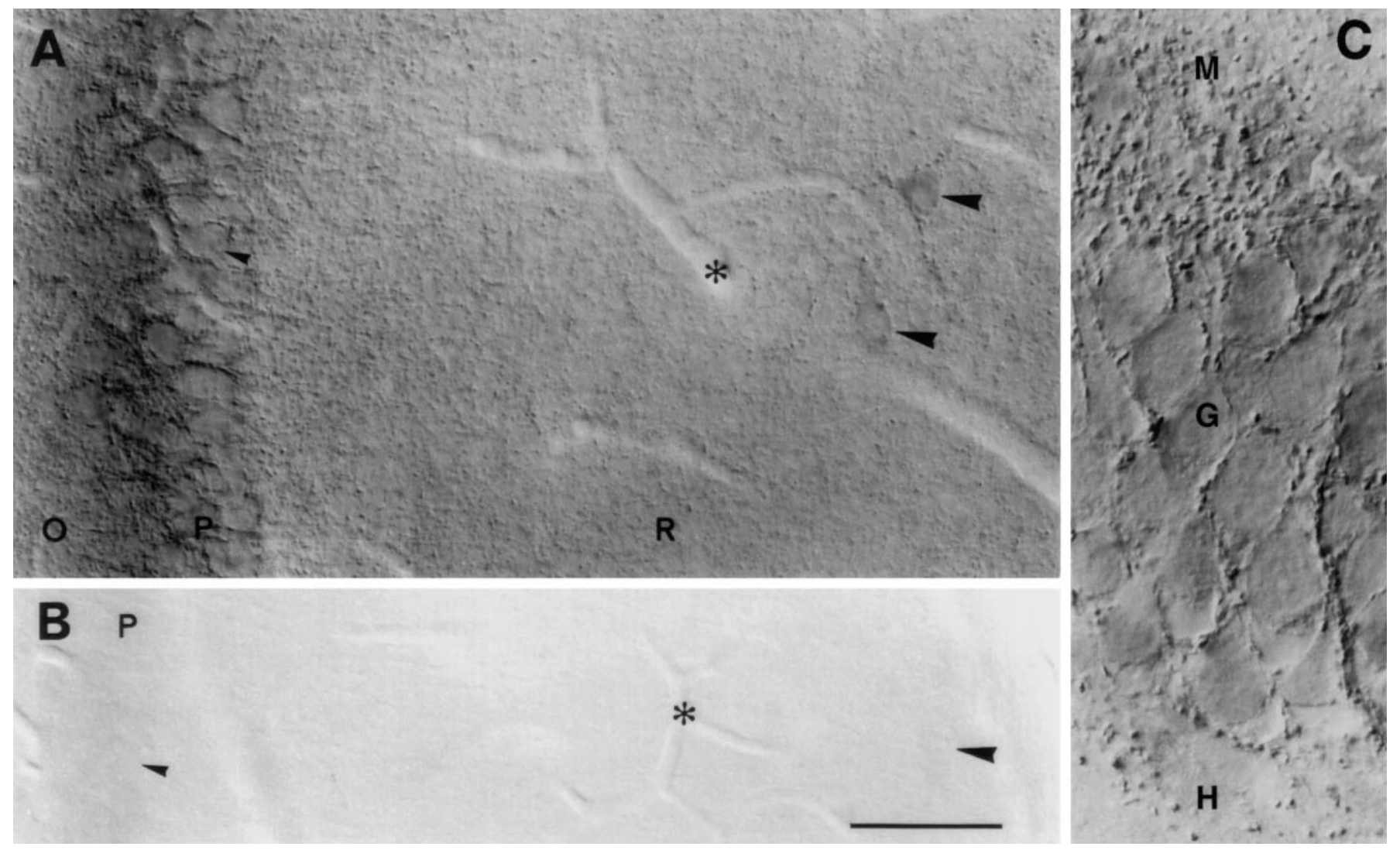

Figure 3. Cellular localization of VGAT in hippocampus CA1 and area dentata by immunoperoxidase staining. $A$, CA1. Nerve terminals containing VGAT are distributed throughout the layers but are concentrated around the perikarya of pyramidal cells (small arrowheads) and interneurons (large arrowheads). The cytoplasm of interneuron perikarya shows immunoreactivity but less intense than that of the nerve endings. (The diff use staining in the pyramidal layer is attributable to the presence of many stained nerve endings below the focal plane.) N2 antibody with Triton. $B$, Section adjacent to that in $A$, processed, photographed, and printed in the same conditions but after absorption of the N2 antibody with $\mathrm{N}$-terminal fusion protein. $C$, Area dentata. VGAT-containing nerve terminals are distributed similarly as in CA1 on the granule cell bodies and in the neuropil. N2 antibody without Triton. $O, P, R$, Strata oriens, pyramidale, and radiatum of hippocampus, respectively; $M, G, H$, strata moleculare, granulare, and hilus (CA4) of area dentata, respectively. Asterisks, Blood vessels (emptied by perfusion). DIC optics (in this and subsequent light micrographs). Scale bar: $A$, $B 50 \mu$ m; $C, 20 \mu \mathrm{m}$

with a subcutaneous injection of the same amounts of fusion protein or conjugated peptide emulsified with Freund's incomplete adjuvant (Life Technologies). Serum was collected $14 \mathrm{~d}$ later and stored at $4^{\circ} \mathrm{C}$ with $0.02 \% \mathrm{NaN}_{3}$ added.

Membrane preparation of cells expressing VGAT. Wild-type PC12 cells and a previously characterized PC12 cell line stably expressing rat VGAT (McIntire et al., 1997) were grown to confluence in DME-H21 medium containing $10 \%$ equine serum and $5 \%$ Cosmic Calf Serum (HyClone, Logan, UT). To prepare membranes, the cells were collected, washed in calcium- and magnesium-free PBS, resuspended in $1 \mathrm{ml}$ of SH buffer (0.3 M sucrose and $10 \mathrm{~mm}$ HEPES-KOH, pH 7.4) with $1.25 \mathrm{~mm}$ Mg-EGTA and protease inhibitors (1 $\mathrm{mm}$ PMSF, $2 \mu \mathrm{g} / \mathrm{ml}$ aprotinin, 2 $\mu \mathrm{g} / \mathrm{ml}$ leupeptin, $1 \mu \mathrm{g} / \mathrm{ml} \mathrm{E} 64$, and $1 \mu \mathrm{g} / \mathrm{ml}$ pepstatin) $/ 15 \mathrm{~cm}$ plate, and disrupted by passage through a cell cracker at a clearance of $10 \mu \mathrm{m}$ (McIntire et al., 1997). The homogenate was centrifuged at 27,000 $\times g$ for $35 \mathrm{~min}$, and membranes in the supernatant were pelleted at $64,000 \times$ $g$ for $1 \mathrm{hr}$ and resuspended in $\mathrm{SH}$ buffer with protease inhibitors (as above).

Preparation of SDS extracts of tissues. SDS extracts from whole rat brain (four adult Sprague Dawley rats) and liver were prepared by homogenizing the tissues in PBS with SDS $(10 \mathrm{mg} / \mathrm{ml}), 5 \mathrm{~mm}$ EDTA, and $1 \mathrm{~mm}$ PMSF with a Dounce homogenizer. The tissue samples were then diluted in SDS sample buffer containing dithiothreitol and immediately separated by SDS-PAGE or stored at $-80^{\circ} \mathrm{C}$.

Electrophoresis and blotting. Thirty micrograms of protein per lane were separated at $140 \mathrm{~V}$ for $\sim 2 \mathrm{hr}$ or at $6 \mathrm{~A}$ overnight. After electrophoresis, the separated samples were electroblotted onto nitrocellulose at $1.2 \mathrm{~mA} / \mathrm{cm}^{2}$. The transfer buffer consisted of $20 \mathrm{~mm}$ Tris-HCl, $150 \mathrm{~mm}$ glycine, and $20 \%$ methanol. Nonspecific binding to the blot was blocked by incubation of the membrane with $5 \%$ nonfat milk protein in PBS containing $0.1 \%$ Tween 20 for $1 \mathrm{hr}$. The blot was then incubated with the antibodies (N2, 1:2000; C1, 1:200 or 1:400) for $2 \mathrm{hr}$ or overnight at room temperature. After washing, blots were treated with peroxidase-linked anti-rabbit $\mathrm{IgG}$, and the complexes were visualized on x-ray film after incubation with enhanced chemiluminescent substrate (Pierce, Rockford, IL).

Tissue for immunocytochemistry. Nine adult rats (Wistar strain; Moellegaard Hansen) of 150-200 gm were deeply anesthetized with pentobarbital $(100 \mathrm{mg} / \mathrm{kg})$, the right atrium was cut open, and the animals were perfused through the left ventricle-aorta. Animal use was according to Norwegian law and in agreement with the guidelines of the Society for Neuroscience. The liquids were delivered by a peristaltic pump at 50 $\mathrm{ml} / \mathrm{min}$. After a brief flush of 4\% Dextran-T70 (molecular weight, 70,000; Pharmacia) in $0.1 \mathrm{M}$ sodium phosphate buffer, $\mathrm{pH} 7.4$ (NaPi), for $10-15$ sec, one of three different fixatives was introduced: (1) for fixative A, two rats were perfused with a mixture of formaldehyde/picric acid/glutaraldehyde $(4 / 0.2 / 0.05 \%)$ in $\mathrm{NaPi}$; (2) for fixative $\mathrm{B}$, four rats were perfused with glutaraldehyde/formaldehyde/picric acid (2.5/1/0.02\%) (Somogyi and Takagi, 1982) in $\mathrm{NaPi}$; and (3) for fixative $\mathrm{C}$, three rats were fixed by formaldehyde/picric acid (4/0.02\%) in $0.1 \mathrm{M}$ sodium acetate buffer, pH 6.0 $(200 \mathrm{ml}, 5 \mathrm{~min})$, followed by the same fixatives in $0.1 \mathrm{M}$ sodium carbonate buffer, pH 10.5 (400 ml, $20 \mathrm{~min}$ ). The latter fixative (Berod et al., 1981; Marcos et al., 1997) had the best preservation of antigenicity and acceptable ultrastructure (Dehnes et al., 1998). The brains were post-fixed in the same fixative overnight at $4^{\circ} \mathrm{C}$ and then kept in diluted fixative $(1: 10$ with the buffer) at $4^{\circ} \mathrm{C}$ until used.

Fixatives $\mathrm{A}$ and $\mathrm{C}$ were used for light and electron microscopic immunoperoxidase; fixatives $\mathrm{B}$ and $\mathrm{C}$ were used for electron microscopic 

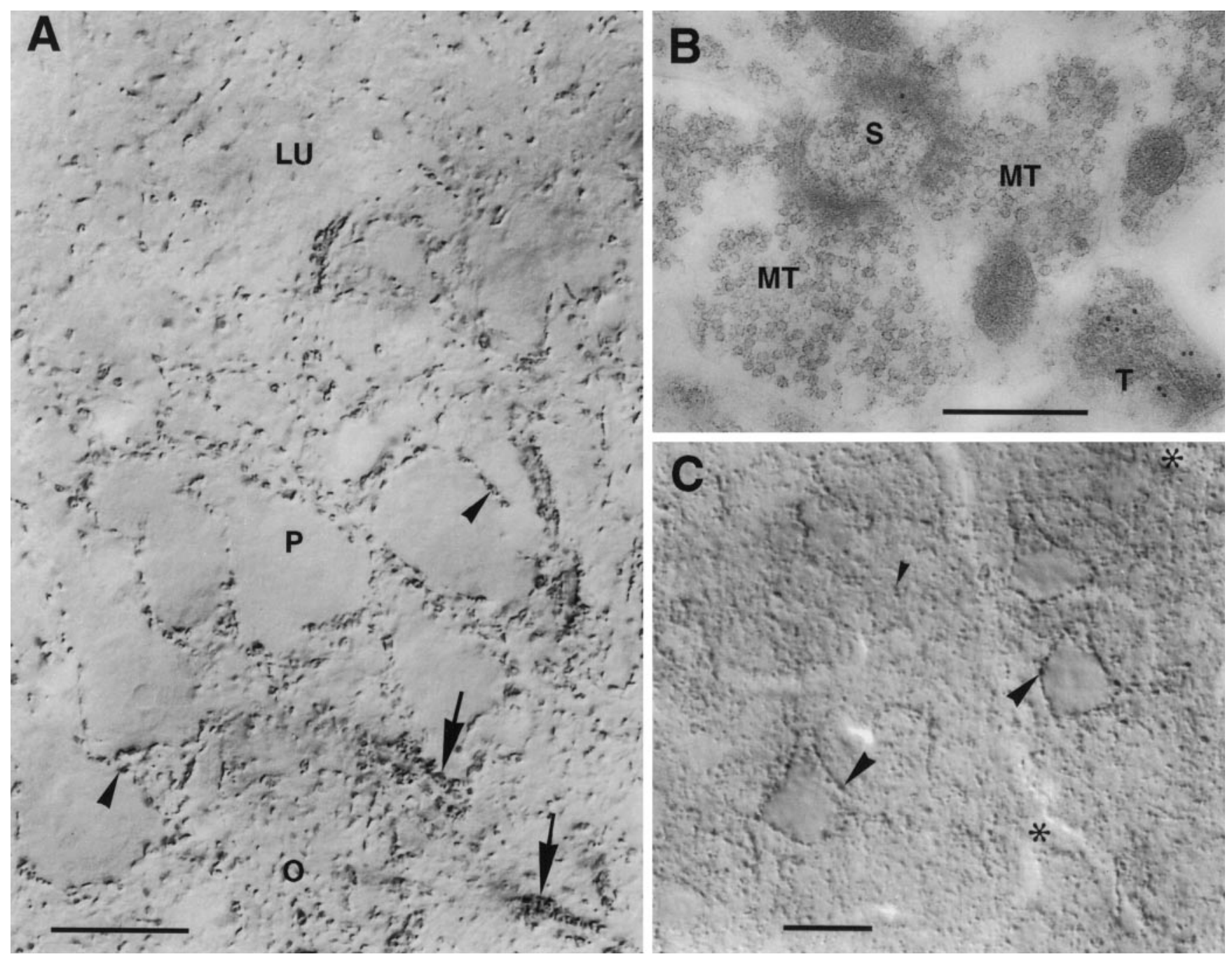

Figure 4. VGAT in hippocampus CA3 and neocortex. $A$, CA3. Nerve endings immunoperoxidase-stained for VGAT are seen to outline unstained pyramidal cell bodies (arrowheads) and the initial parts of their axons (arrows) or are spread in the neuropil. Mossy fiber terminals in the stratum lucidum $(L U)$ are not visualized. $P, O$, Strata pyramidale and oriens, respectively. $B$, CA3, stratum lucidum. Post-embedding immunogold labeling shows VGAT in a terminal with pleomorphic vesicles $(T)$ but not in the large mossy fiber terminals $(M T)$ making asymmetric synapses on a spine $(S)$. $C$, Limb area of parietal cortex, layer 5. Strongly immunoreactive (peroxidase with Triton) nerve terminals are concentrated along pyramidal cell perikarya (large arrowheads) and are spread in the neuropil (small arrowheads). On the apical parts of the three large pyramidal cells shown, VGAT-containing boutons on the back or front of the cells can be seen en face (in part slightly out of focus). Asterisks, Blood vessels. Scale bars: $A, 20 \mu \mathrm{m} ; B, 0.5 \mu \mathrm{m} ; C, 25 \mu \mathrm{m}$.

immunogold labeling. Fixative $\mathrm{C}$ was used for all immunogold illustrations and quantification, except for the double- and triple-labeling experiments, which require glutaraldehyde for demonstration of fixed amino acids.

Pre-embedding immunoperoxidase. Vibratome sections (40 $\mu \mathrm{m}$ thick) were cut $\left(4-10^{\circ} \mathrm{C}\right)$ and stored $\left(4^{\circ} \mathrm{C}\right.$ overnight to 3 weeks $)$ in $\mathrm{NaPi}$ containing $\mathrm{NaN}_{3}(0.1 \%)$. Then the sections were rinsed in $\mathrm{NaPi}$, incubated $(30 \mathrm{~min})$ in buffer $\mathrm{A}(0.135 \mathrm{M} \mathrm{NaCl}$ and $0.01 \mathrm{M}$ sodium phosphate buffer, $\mathrm{pH} 7.4)$, incubated in buffer $\mathrm{B}(0.3 \mathrm{M} \mathrm{NaCl}$ and $0.1 \mathrm{M}$ Tris- $\mathrm{HCl} \mathrm{pH}$ 7.4) with $10 \%(\mathrm{v} / \mathrm{v})$ newborn calf serum and then incubated (overnight at room temperature) with primary antibodies diluted $(1: 200-1: 2000)$ in buffer C (buffer B with 1\% newborn calf serum). Triton X-100 (Triton; $0.1 \%$ in buffers B and C) was included only when stated. When not stated otherwise, the illustrations are from sections treated with N2 antibody (1:200 without Triton or 1:1000 with Triton); for illustrations, C1 antibody was used at 1:400 (with Triton). The sections were subsequently washed (three times for $1 \mathrm{~min}$ each and two times for 10-20 min each) in buffer $\mathrm{C}$, incubated $(1 \mathrm{hr})$ with biotinylated donkey anti-rabbit $\mathrm{Ig}$ (1:100; Amersham, Arlington Heights, IL) in buffer C, washed (three times for $1 \mathrm{~min}$ each and two times for $15 \mathrm{~min}$ each) in buffer $\mathrm{C}$, incubated $(1 \mathrm{hr})$ with streptavidin-biotinylated horseradish peroxidase complex (1:100; Amersham) in buffer $C$, and washed (three times for 1 min each and two times for 15 min each) in buffer $\mathrm{C}$. Then the sections were washed (three times for $1 \mathrm{~min}$ each) in buffer A, preincubated for $5 \mathrm{~min}$ in $\mathrm{NaPi}$ with diaminobenzidine $(0.5 \mathrm{mg} / \mathrm{ml})$, and then incubated for $6 \mathrm{~min}$ in the same solution containing $\mathrm{H}_{2} \mathrm{O}_{2}(0.1 \mathrm{mg} / \mathrm{ml})$. The reaction was stopped by rinsing with $\mathrm{NaPi}$ (two times for $3 \mathrm{~min}$ each). For light microscopy, Vibratome sections were mounted in glycerol-gelatin. Brain areas were identified referring to the atlas of Paxinos and Watson (1986). For medium- and high-power light microscopy, sections were photographed by a Leica (Nussloch, Germany) photomicroscope with differential interference contrast (DIC) optics. For electron microscopy, the sections were treated with osmium (30-45 min, $10 \mathrm{mg} / \mathrm{ml}$ in $\mathrm{NaPi}$ ) washed (three times for $1 \mathrm{~min}$ each) in $\mathrm{NaPi}$, dehydrated in graded ethanols $(50,70,80$, and $96 \%$ one time for 5 min each and $100 \%$ three times for $10 \mathrm{~min}$ each) and propylene oxide (two times for $5 \mathrm{~min}$ each), and embedded in Durcupan ACM. Ultrathin sections were cut and contrasted $(10 \mathrm{mg} / \mathrm{ml}$ uranyl acetate for $10-15 \mathrm{~min}$ and $3 \mathrm{mg} / \mathrm{ml} \mathrm{Pb}$ citrate for 1-2 $\mathrm{min}$ ) before viewing in a Phillips CM10 electron microscope.

Post-embedding immunogold labeling. The freeze-substitution embedding and immunogold labeling were performed as described (Chaudhry et al., 1995). Small rectangular pieces of aldehyde-perfused brain were cut by a razor blade, rinsed in $\mathrm{NaPi}$, and immersed in 10 and $20 \%$ 

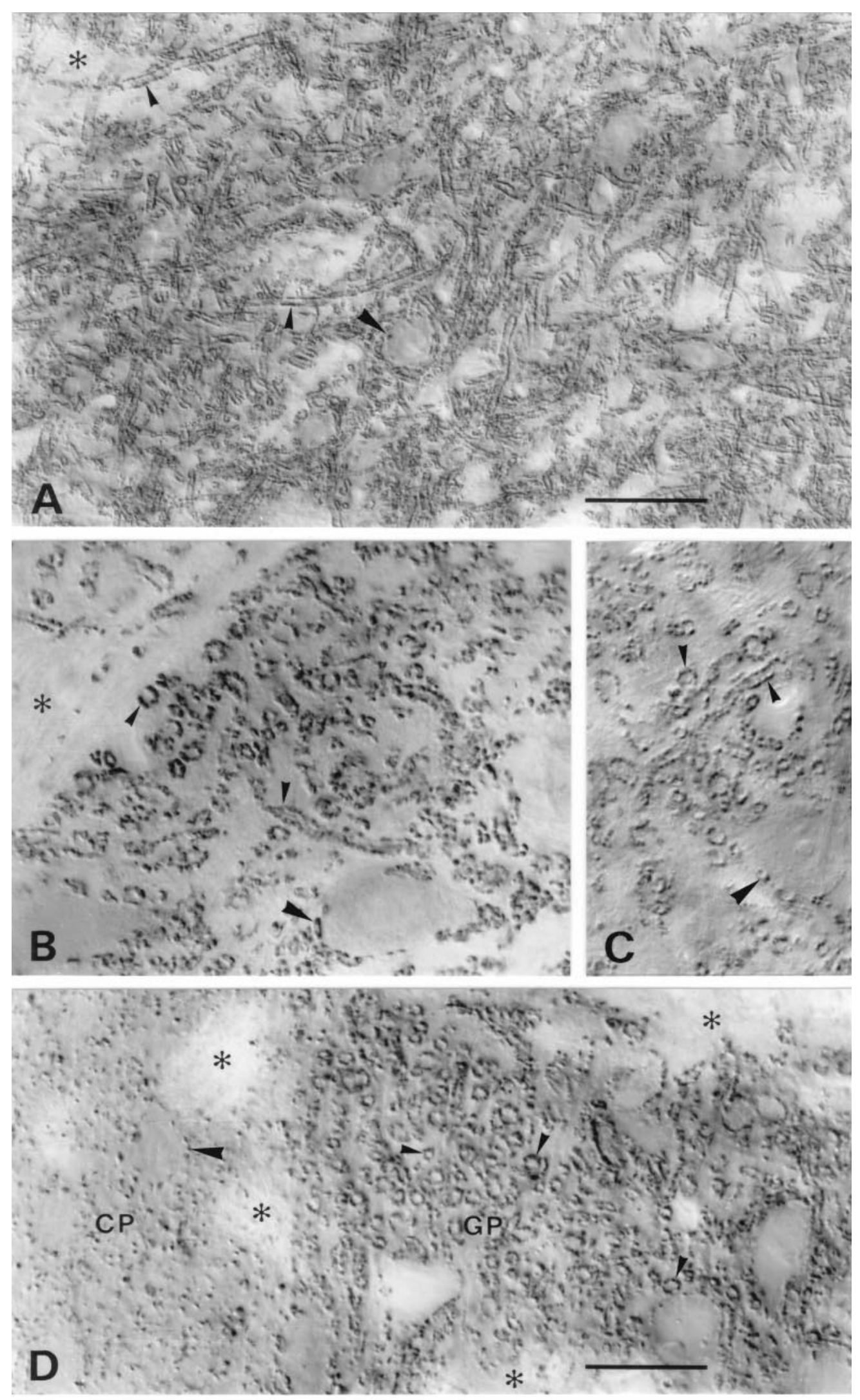

Figure 5. VGAT in basal ganglia and substantia nigra. $A-C$, Substantia nigra pars reticulata. $D$, Border between caudatoputamen $(C P)$ and globus pallidus $(G P) . A, D, \mathrm{~N} 2$ antibody with Triton. $B$, N2 antibody without Triton. $C, \mathrm{C} 1$ antibody with Triton. VGAT-containing small nerve endings coat dendrites (small arrowheads) very densely and perikarya (large arrowheads) less completely. The staining pattern in substantia nigra and globus pallidus is typical of the GABAergic afferents from caudatoputamen. Antibodies to the $\mathrm{N}$ terminus $(A, B, D)$ and $\mathrm{C}$ terminus $(C)$ of VGAT show the same localization with $(A, C, D)$ and without $(B)$ Triton. Asterisks, Bundles of unstained nerve fibers. Scale bars: $A, 50 \mu \mathrm{m} ; B-D$, $20 \mu \mathrm{m}$. glycerol in $\mathrm{NaPi}$ for $0.5 \mathrm{hr}$ and subsequently in $30 \%$ glycerol in $\mathrm{NaPi}$ overnight at $4^{\circ} \mathrm{C}$. The tissue samples were frozen by plunging into liquid propane cooled to $-190^{\circ} \mathrm{C}$ by liquid nitrogen in a KF80 Universal Cryofixation System (Leica, Vienna, Austria). The tissue samples were then moved to a Cryo Substitution Apparatus (Leica) precooled to $-90^{\circ} \mathrm{C}$, where the samples were substituted with anhydrous methanol containing $0.5 \%$ uranyl acetate. After washing several times with methanol, the samples were infiltrated at $-45^{\circ} \mathrm{C}$ with stepwise increasing 

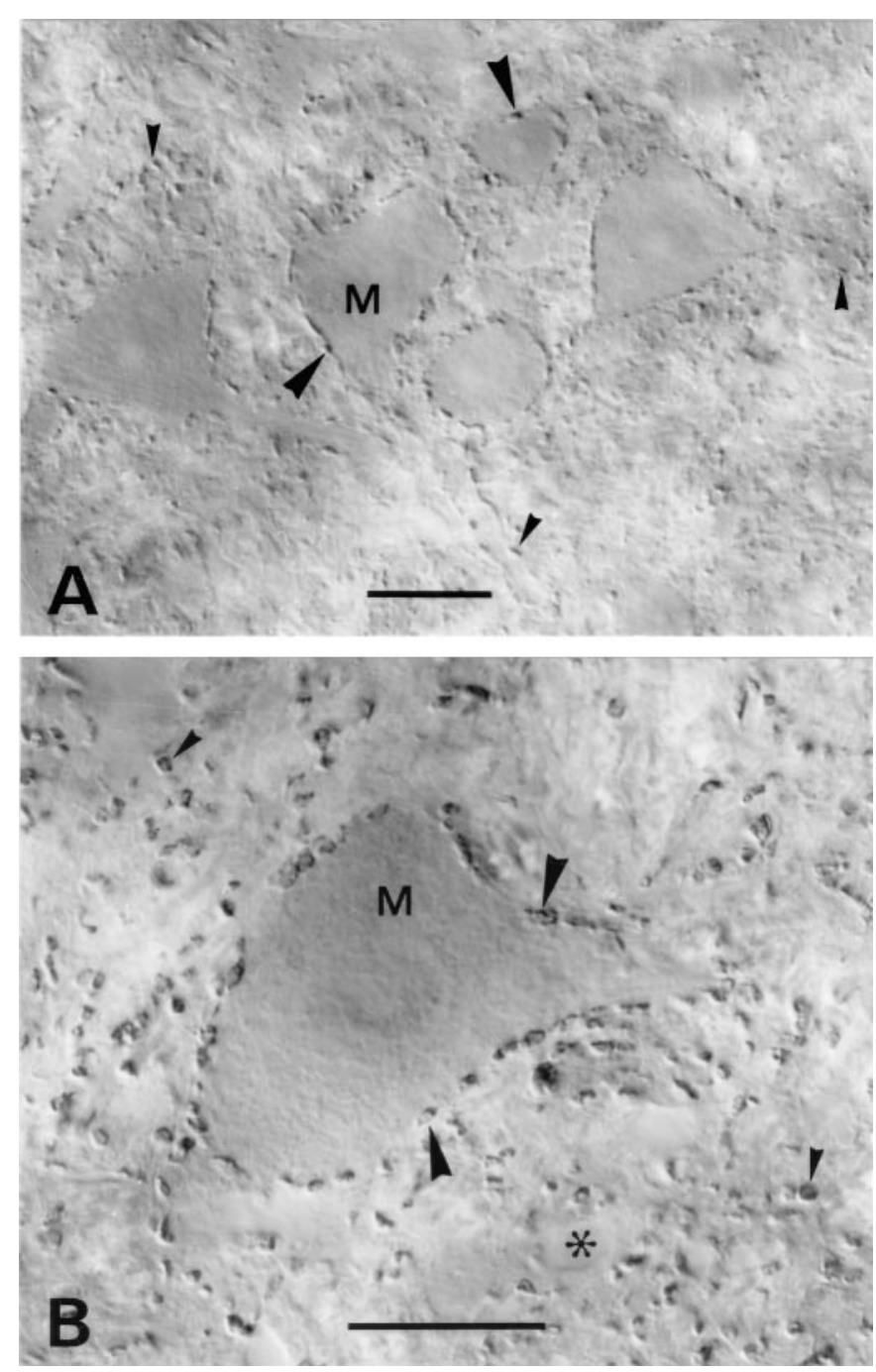

Figure 6. VGAT in motor nuclei. $A$, Medulla spinalis, ventral horn in an upper cervical segment. $B$, Nucleus facialis. Immunoreactive nerve terminals outline motoneuron perikarya ( $M$, arrowheads). A high proportion of the terminals contacting these perikarya are known to contain glycine, alone or in addition to GABA. VGAT-containing terminals in the neuropil (small arrowheads) are sometimes seen to contact dendrites. Asterisk, Empty blood vessel. Scale bars: $A, 25 \mu \mathrm{m} ; B, 20 \mu \mathrm{m}$.

concentrations of Lowicryl HM20 to methanol and subsequently with pure Lowicryl HM20 overnight. The resin was polymerized in embedding malls catalyzed by ultraviolet light of $360 \mathrm{~nm}$ wavelength for $2 \mathrm{~d}$ at $-45^{\circ} \mathrm{C}$. Ultrathin sections $(80-90 \mathrm{~nm})$ were cut on a Leica ultramicrotome with a diamond knife and put on 500 mesh nickel grids. Serial sections, for processing with three different antibodies, were put on one-hole grids with a carbon-coated Formvar film. Sections were washed with $0.1 \%$ sodium borohydride and $50 \mathrm{~mm}$ glycine in TBST $(0.05 \mathrm{M}$ Tris- $\mathrm{HCl}, \mathrm{pH} 7.4,0.9 \%$ sodium chloride, and $0.1 \%$ Triton), blocked in TBST containing $2 \%$ human serum albumin, and then incubated with the primary antibody diluted (1:20-1:40) in the same blocking solution overnight at $4^{\circ} \mathrm{C}$. They were subsequently washed with TBST and incubated with goat anti-rabbit Ig coupled to $15 \mathrm{~nm}$ gold particles (GAR15; Amersham, Buckinghamshire, UK; diluted 1:20 in TBST) for $1 \mathrm{hr}$. The sections were then, after washing with water, stained with uranyl acetate (10 min) and lead citrate $(1 \mathrm{~min})$.

Electron micrographs were taken in a Phillips CM10 electron microscope. Structures were identified referring to descriptions by Palay and Chan-Palay (1974) and Peters et al. (1991). The concentrations of gold particles were measured by means of the data program MORFOREL (Blackstad et al., 1990). The vesicular association of the gold particles was analyzed in two different ways: (1) The occurrence of synaptic vesicles and gold particles was recorded within squares of a lattice placed over the pictures (Ji et al., 1991). Particles or vesicles touching the sides of the squares were included only for the bottom and right sides. Squares containing mitochondria or partly outside an axon terminal were excluded. (2) The centers of synaptic vesicles and gold particles, as well as the circumference of the terminal and any intraterminal mitochondria and areas filled with filament bundles (in basket cell axons), were recorded on a digitizing tablet by the program Micro Trace (Leergaard and Bjaalie, 1995). Custom software was used to determine the intercenter distances from each gold particle to the nearest synaptic vesicle (Gundersen et al., 1998). This was compared with distances to vesicles from points randomly distributed over the mitochondria and filamentfree parts of the VGAT-labeled nerve terminals. Statistical analyses of means and of the correlation of vesicles with immunogold particles were performed by the Statistica package, the distributions of intercenter distances were compared using the $\chi^{2}$ test for equality of distributions provided by the University of Amsterdam (http://fonsg3.let.uva.nl).

Antibodies. The VGAT antisera from the rabbits (N1 and N2) immunized with the N-terminal fusion protein and the rabbits $(\mathrm{C} 1$ and $\mathrm{C} 2)$ immunized with the synthetic $\mathrm{C}$-terminal peptide were incubated overnight in $0.1 \%$ Tween 20 containing 5\% nonfat dry milk (Carnation, Los Angeles, CA), $1 \%$ goat serum, and $40 \mathrm{mg} / \mathrm{ml}$ rat liver acetone powder (Cappel, West Chester, PA). Then the solutions were transferred to centrifuge tubes with a $0.45 \mu \mathrm{m}$ filter insert and spun in a Microfuge for 5 min at maximum speed. The N2 serum was used when not stated otherwise. For negative control, the diluted antibodies were absorbed overnight with $\mathrm{N}$-terminal fusion protein or $\mathrm{C}$-terminal synthetic peptide. Likewise, omission of antibody or substitution with nonimmune serum abolished labeling.

Antibody to the GABA transporter GAT-1 was obtained from a rabbit (68514) immunized with the C-terminal peptide EQPQAGSSASKEAYI (amino acid residues 584-599 of rat GAT-1) (Guastella et al., 1990) conjugated to keyhole limpet hemocyanin by glutaraldehyde. Preparation of antigen, immunization, and purification of antibody followed procedures previously used for glutamate transporters (Lehre et al., 1995). The antibody was affinity-purified on the peptide immobilized on agarose, absorbed with immobilized carrier protein treated with glutaraldehyde, and concentrated by immobilized protein A. It was used for immunoperoxidase staining at $0.6 \mu \mathrm{g} / \mathrm{ml}$ with Triton.

Antiserum to aldehyde-fixed glycine (290; Kolston et al., 1992) was diluted to $1: 1000$ and absorbed with $200 \mu \mathrm{M}$ GABA previously reacted with glutaraldehyde (GABA-G), $50 \mu \mathrm{M} \quad$ L- $\alpha$-alanine-G, $50 \mu \mathrm{M}$ $\beta$-alanine-G, and $50 \mu \mathrm{M}$ glutamine-G in TBST containing $2 \%$ human serum albumin (HSA) overnight before use. The antiserum to aldehydefixed GABA (990; Walberg and Ottersen, 1992) was diluted 1:1500 and absorbed with $200 \mu \mathrm{M}$ glutamate-G, also in TBST containing $2 \%$ HSA, overnight before use. The antibodies to GABA and to glycine were generated according to the methods established for amino acid immunocytochemistry (Storm-Mathisen et al., 1983) and have been characterized for electron microscopic post-embedding immunogold labeling (Örnung et al., 1994, 1996). Ultrathin test sections of embedded amino acid conjugates (Ottersen, 1989), included with the tissue sections processed with sera 900 and 290, ascertained that significant densities of gold particles occurred only over fixed GABA or glycine, respectively, and not over conjugates of other fixed amino acids or over aldehyde-fixed brain macromolecules in the present conditions.

and electron microscopic $(D)$ immunoperoxidase staining shows VGAT-containing nerve terminals in the neuropil (small arrowheads) densely outlining perikarya and stem dendrites of the large immunonegative neurons (large arrowheads). Boutons in this position are mainly terminals of Purkinje cell axons. The nuclei are pierced by immunonegative, refringent bundles of myelinated axons $(a)$. Terminals are often lightly stained in their centers; electron microscopy shows this to be attributable to centrally placed mitochondria $(m)$. A postsynaptic dendrite $(D)$ is immunonegative despite being opened to penetration of reagents at the Vibratome cut (star). Asterisks, Blood vessels. Scale bars: $A, B, 25 \mu \mathrm{m} ; C, 20 \mu \mathrm{m} ; D, 1 \mu \mathrm{m}$. 

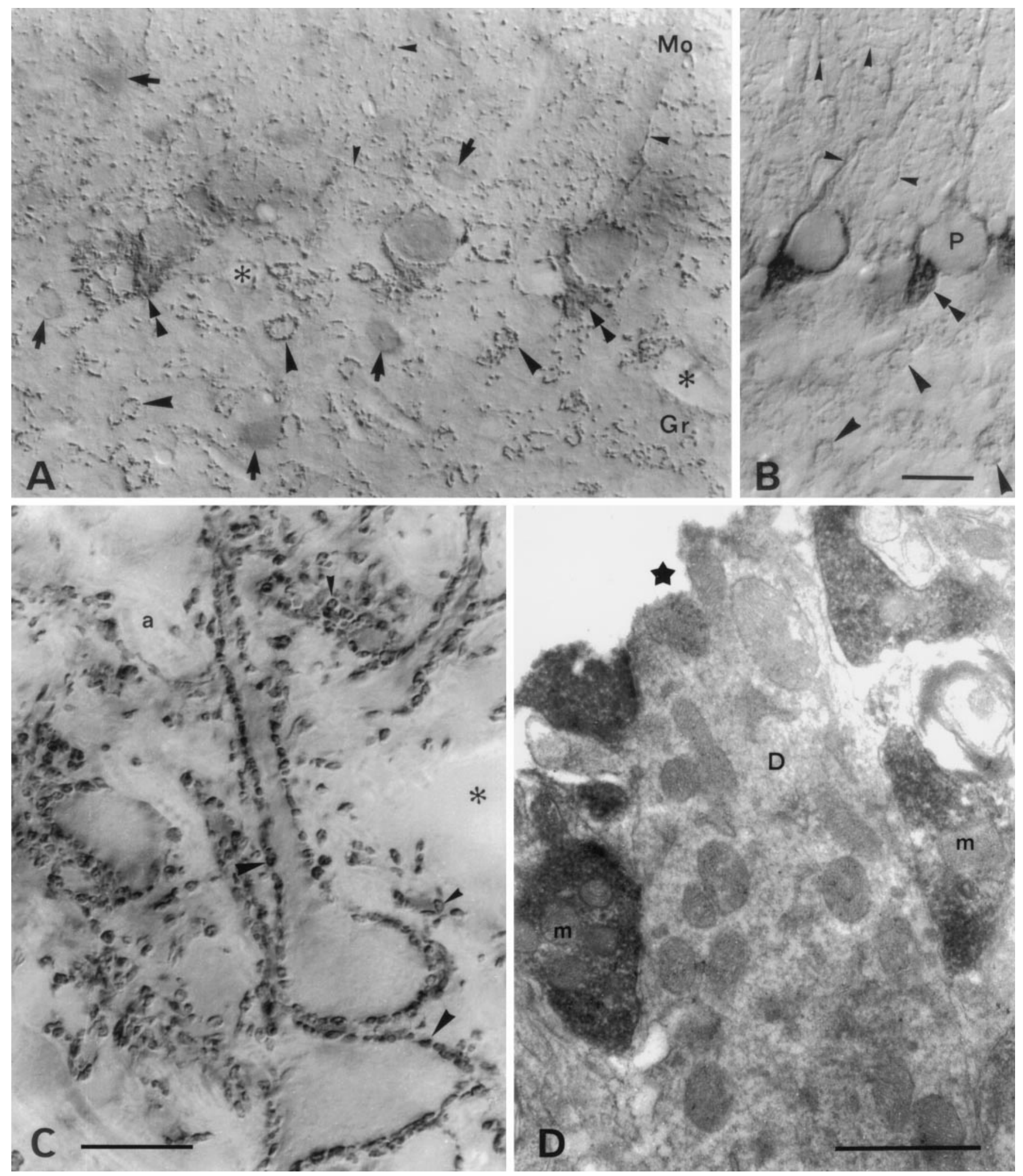

Figure 7. VGAT and GAT-1 in cerebellum. $A$, VGAT; $B$, GAT-1 in the cortex cerebelli. VGAT is concentrated in nerve terminals, whereas GAT-1, a plasma membrane protein, is found in terminals and axons. Both proteins are localized in the mixed GABAergic-glycinergic terminals (deriving from Golgi cells) arranged in rosettes outlining glomeruli in the granular layer (large arrowheads), as well as in the predominantly GABAergic axons and terminals of the molecular layer (small arrowheads) (deriving from stellate cells and stellate basket cells). The axons and terminals from stellate cells can be seen forming a plexus in the molecular layer. Around the initial axon segments of Purkinje cells the axons and terminals of basket cells form a dense plexus called a pinceau (double arrowheads). There is some staining for VGAT in the cytoplasm of the perikarya of stellate, basket, and Golgi cells (arrows), and Purkinje cells $(P) . M o, G r$, molecular and granular layers, respectively. Asterisks, Empty blood vessels. Parasagittal sections of hemisphere, lobus anterior. $C, D$, VGAT in nucleus interpositus (a central cerebellar nucleus). Light microscopic $(C)$ (Figure legend continues on preceding page) 


\section{RESULTS}

\section{Antibodies to VGAT}

The antibodies N2 to the N-terminal fusion protein and C1 to the $\mathrm{C}$-terminal peptide showed the best staining of immunoblots and were selected for further study. N2 stained one band on immunoblots of PC12 cells expressing VGAT and in extracts of whole rat brain (Fig. 1, left). The apparent molecular mass of the band $(55-60 \mathrm{kDa})$ is in agreement with that calculated from the amino acid composition. There was no staining of liver or control PC12 cells under the same conditions. $\mathrm{C} 1$ also stained a single electrophoretic band of the same molecular mass in extracts of VGATexpressing PC12 cells, but in brain extracts there was an additional band of lower molecular mass (Fig. 1, right). The nature of this band is not resolved. The results below are therefore based on the N2 antiserum unless explicitly stated otherwise. However, except for a lower signal and higher background with the $\mathrm{C} 1$ antiserum, immunocytochemical results with the two antibodies were in agreement (see below).

\section{Immunoperoxidase localization}

Survey of the brain with N2 antibody (Fig. $2 A$ ) showed a distribution of VGAT immunoreactivity similar to those of recognized GABAergic markers glutamate decarboxylase (GAD) (Mugnaini and Oertel, 1985), GABA content and high-affinity GABA uptake (Ottersen and Storm-Mathisen, 1984), i.e., high-intensity staining in target areas of short-axon and long-axon GABAergic neurons. (In the present paper the terms "GABAergic" and "glycinergic" neurons are used to designate neurons containing high concentrations of GABA and glycine, respectively, in their nerve endings and hence being likely to use these amino acids as transmitters.) Examples of GABAergic long-axon targets are globus pallidus, ventral pallidum, nucleus entopeduncularis, substantia nigra pars reticulata, vestibular nuclei, and central cerebellar nuclei. Examples of densely innervated GABAergic shortaxon targets are the pyramidal and granular layers of hippocampus and area dentata, caudatoputamen, amygdaloid area, and the Purkinje cell layer of the cerebellar cortex, as well as the superficial layers of the colliculus superior, the dorsal nucleus cochlearis, and the nucleus tractus spinalis nervi trigemini. The $\mathrm{C} 1$ antibody (Fig. $2 B$ ) showed an almost identical distribution. (The slight differences apparent in Fig. $2 A, B$ are explainable by a slight difference in overall staining intensity.)

Higher magnification revealed that the VGAT staining pattern was attributable to intensely immunoreactive nerve terminal-like dots ("puncta") present in all regions but at different densities. (Below, these are referred to as "nerve endings" or "terminals," because subsequent electron microscopy established this identity; see below.) In hippocampus (Figs. 3, 4) such dots were spread throughout the cortical layers but were concentrated on the surfaces of the perikarya of the principal neurons (pyramidal cells) and interneurons. This distribution matches that of GAD (StormMathisen and Fonnum, 1971; Barber and Saito, 1976; Somogyi et al., 1983b), GABA (Storm-Mathisen et al., 1983), high-affinity GABA uptake (Hökfelt and Ljungdahl, 1971; Taxt and StormMathisen, 1984), and GABA transporter GAT-1 (Radian et al., 1990; Ribak et al., 1996b). In strata oriens and pyramidale rows of VGAT-immuoreacive dots (Fig. $4 A$ ) evidently represent the terminals of axoaxonic (chandellier) cells (Somogyi et al., 1983b). Hippocampal interneurons are known to be GABAergic and the source of the major part of the GABAergic nerve terminals in the region (Storm-Mathisen, 1972; Schlander et al., 1987; Soriano et al., 1990; Frotscher et al., 1992; Hálasy and Somogyi, 1993; Hálasy et al., 1996; Ceranik et al., 1997). Interneuron perikarya showed VGAT staining in the cytoplasm (Fig. $3 A$ ), probably representing the protein before insertion into the plasma membrane. Such staining was not shown by the perikarya of pyramidal or granular cells (Figs. 3C, 4A). The axons of the latter, the hippocampal mossy fibers, give rise to boutons that are thought to be glutamatergic but are also enriched with GABA (Sandler and Smith, 1991). These showed no VGAT immunoreactivity (Fig. 4A,B), in agreement with the low staining intensity in stratum lucidum (Fig. 2) and lack of staining of their parent cell bodies (Fig. 3C).

In the cerebral neocortex (Fig. 4C), VGAT-immunoreactive dots were distributed similarly as in hippocampal archicortex, consistent with the distribution of nerve terminals that contain GAD and GABA, and accumulate GABA by high-affinity uptake and retrograde axonal transport (Hökfelt and Ljungdahl, 1972; Freund et al., 1983; Somogyi et al., 1981, 1983a, 1984, 1998).

In the basal ganglia (Fig. 5) VGAT-immunoreactive terminals were quite numerous in the caudatoputamen but by far more concentrated in the target nuclei of the main GABAergic projections globus pallidus (Fig. 5D) and substantia nigra (Fig. 5A-C). In the latter nuclei small immunopositive terminals could be seen to densely outline the dendrites of unstained target neurons. This is the typical pattern of GABAergic nerve terminals first revealed by GAD immunocytochemistry (Ribak et al., 1976).

Motoneurons in motor nuclei of the brainstem and spinal cord were likewise decorated with VGAT-immunoreactive nerve terminals (Fig. 6). The distribution would be consistent with the combined distributions of GABA-containing and glycinecontaining nerve endings on the surfaces of motoneurons (Yoshida and Tanaka, 1989; Shupliakov et al., 1993; Wentzel et al., 1993; Taal and Holstege, 1994; Örnung et al., 1994, 1996, 1998; Lahjouji et al., 1996; Yang et al., 1997). Most of the terminals synapsing on the somata of spinal motoneurons are reported to be immunoreactive for glycine rather than GABA, a substantial additional proportion being immunoreactive for both glycine and GABA, whereas only very few terminals contain GABA but no glycine. Furthermore, most of the terminals contain the neuronal glycine transporter GLYT2 (Zafra et al., 1995). The results illustrated in Figure 6 therefore strongly suggest that VGAT is present in glycinergic as well as mixed GABAergic-glycinergic terminals on motoneurons.

In the cerebellar cortex (Fig. 7) there are three main types of GABAergic interneurons (stellate and basket cells of the molecular layer and Golgi cells of the granular layer) and one type of GABAergic projection neuron (Purkinje cells, the output neurons of the cerebellar cortex). Of these, Golgi cells are mixed GABAergic-glycinergic, synapsing on granule cell dendritic digits at the periphery of cerebellar glomeruli. The other types are enriched with GABA but not glycine in their terminals (Ottersen et al., 1988). We found VGAT to be enriched in the terminals of all four categories of neurons (Fig. 7). Stained stellate cell terminals outlined unstained Purkinje cell dendrites in the molecular layer (Fig. 7A). Stained basket cell terminals outlined the Purkinje cell bodies forming the dense plexus of preterminal axons ("pinceau") surrounding the Purkinje cell axon hillock. Stained Golgi cell terminals formed the characteristic rosettes outlining cerebellar glomeruli in the granular layer. The plasma membrane GABA transporter GAT-1 was demonstrated for comparison (Fig. 7B). This protein is localized in terminals and axons of cerebellar GABAergic neurons (Radian et al., 1990; Itouji et al., 1996; Morara et al., 1996), except in those of Purkinje cells, which lack a GABA transporter in their plasma membrane (Storm- 

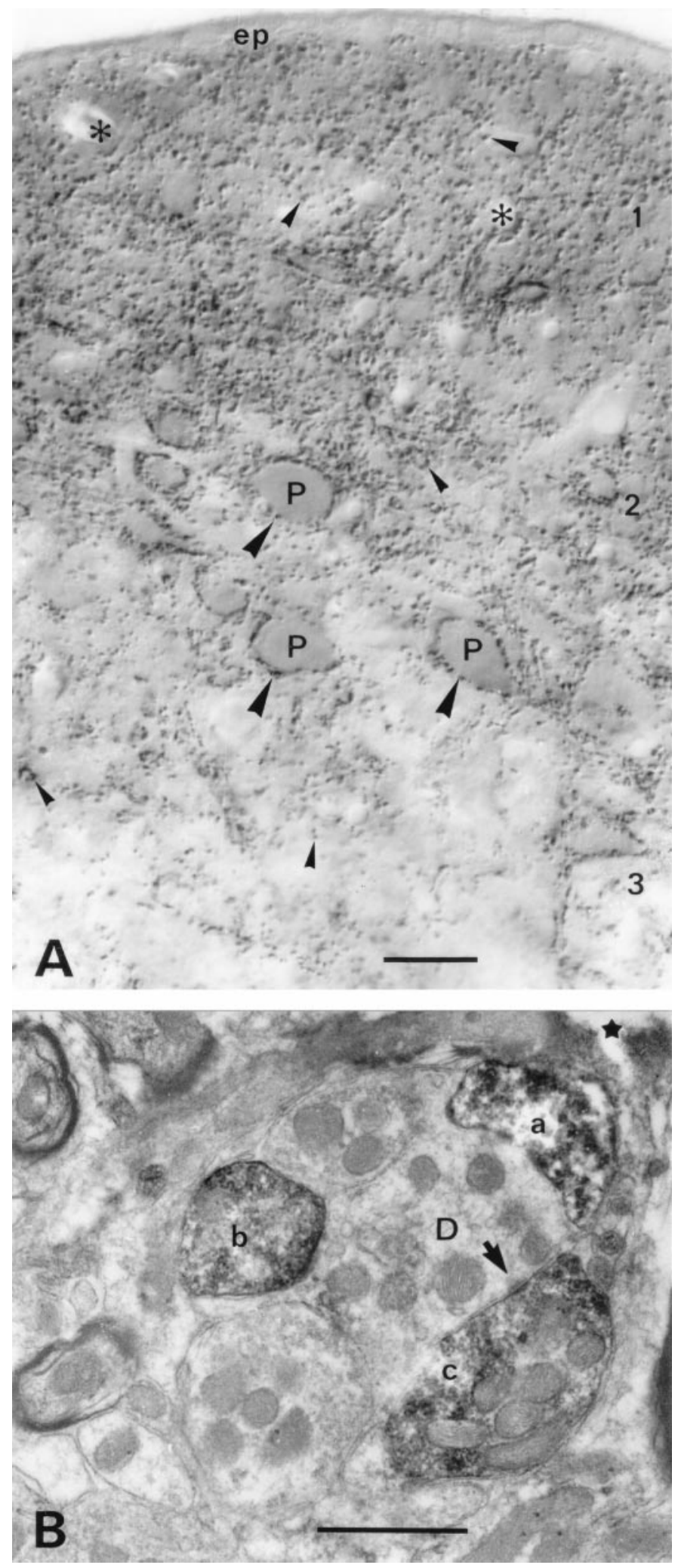

Figure 8. VGAT in nucleus cochlearis dorsalis. $A$, Light microscopic immunoperoxidase staining shows VGAT-containing nerve terminals in the neuropil (small arrowheads), where some of them can be seen to outline dendrites. Perikarya of pyramidal cells ( $P$, fusiform cells) in layer 2 are densely surrounded with VGAT-immunoreactive terminals (large arrowheads). The highest concentration of VGAT-positive nerve endings is found in the two superficial layers. (The diffuse darkening between the immunoreactive terminals here is attributable to numerous similar
Mathisen, 1975; Ribak et al., 1996a). (They are mainly located in the subcortical nuclei.) The cortical distribution of GAT-1 was similar to that of VGAT (and GABA and GAD), but axons en route to the terminals were stained in addition to the terminals themselves. GABAergic as well as mixed GABAergic-glycinergic neurons had some VGAT immunoreactivity in their perikarya (Fig. 7A).

Purkinje cell terminals, the first GABAergic terminals to be identified in vertebrate brain (Fonnum et al., 1970), are rich in GAD (Oertel et al., 1981). They are easily identified in the lateral vestibular nuclei and in the cerebellar nuclei (Fig. $7 C, D$ ), where they form synapses densely distributed along the surface of neuronal perikarya and dendrites. These rather large terminals were shown to be immunoreactive for VGAT. A lighter center visible light microscopically in many of the boutons (Fig. 7C) could be seen electron microscopically to be attributable to clusters of mitochondria displacing synaptic vesicles from the terminal center (Fig. 7D).

In the dorsal nucleus cochlearis (Fig. 8A) VGATimmunoreactive nerve terminals were densely distributed in the neuropil of the superficial layers (layers 1 and 2), partly outlining perikarya and dendrites (Fig. $8 B$ ). As in the motor nuclei, the distribution is compatible with the combined distributions of GABA-positive and glycine-positive nerve endings (Wenthold et al., 1987; Osen et al., 1990; Kolston et al., 1992; Ottersen et al., 1995; Juiz et al., 1996).

In the lateral oliva superior (LSO) (Fig. 9), perikarya and dendrites were densely studded with VGAT-immunoreactive nerve terminals. Originating from glycinergic cells in the medial nucleus of the corpus trapezoideum, most of these terminals are known to be immunopositive for glycine rather than for GABA (Wenthold et al., 1987; Helfert et al., 1989, 1992; Glendenning et al., 1991; Ottersen et al., 1995) and show immunoreactivity for the neuronal glycine transporter GLYT2 in their plasma membrane (Zafra et al., 1995). Again, this strongly indicates that VGAT is present in glycinergic, non-GABAergic nerve endings.

\section{Immunogold localization}

The post-embedding immunogold approach was applied for better resolution and quantification, using ultrathin sections of tissue prepared to optimize preservation of immunoreactivity and ultrastructure (Chaudhry et al., 1995; Dehnes et al., 1998). In various brain regions this method produced results (Fig. 10) in agreement with those obtained by immunoperoxidase. Types of terminals immunoreactive with the latter method were also immunogold-labeled in regions including the cerebellar cortex and nuclei (Fig. 10A-D,F), hippocampus (Figs. 4B, 10E), caudatoputamen (Fig. 10G), and cochlear nuclei (Fig. 10H). Putative glutamatergic terminals, forming asymmetric synapses on dendritic spines, were not immunoreactive (Fig. 10C,E, G, $M, T^{\prime}$ ). The C1 antibody labeled the same terminals (Fig. 10B) or the same type of terminals (Fig. 10D) as the N2 antibody in adjacent

terminals below the focus plane.) The distribution of immunoreactivity is compatible with the combined distributions of GABA-containing and glycine-containing nerve endings (see Results). B, Electron microscopy confirms that the immunoreactive structures are nerve endings $(a-c)$, one of which can be seen to form a symmetric synaptic contact (arrow). $D$, Dendrite; 1-3, layers of the nucleus; ep, ependyma. Asterisks, Blood vessels; star, surface of Vibratome section. Parasagittal sectioning plane. Scale bars: $A, 25 \mu \mathrm{m} ; B, 0.5 \mu \mathrm{m}$. 

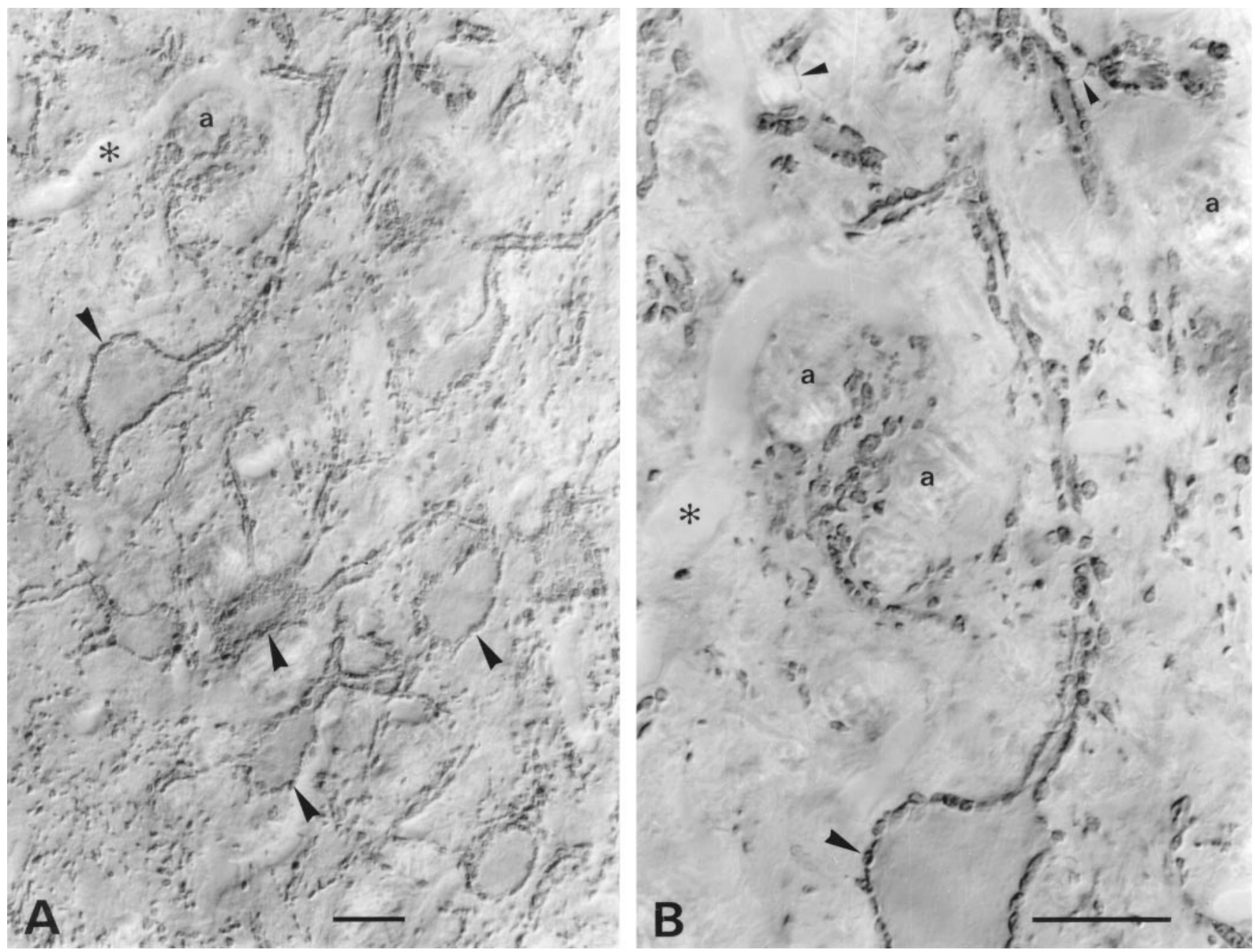

Figure 9. VGAT in mainly glycinergic nerve endings in the LSO. Light microscopic immunoperoxidase staining at intermediate $(A)$ and high $(B)$ magnification is shown. Stained nerve endings (large arrowheads), partly of large size, densely outline perikarya and stem dendrites of unstained LSO neurons. These boutons are known to be mainly glycinergic. Some of the stained boutons are shown en face on the surface of perikarya graced by the section. Others can be seen to be continuous with stained axons (small arrowheads). The nucleus is pierced by tiny bundles of unstained myelinated axons (a). Asterisks, Empty blood vessel. Parasagittal sectioning plane. Scale bars, $20 \mu \mathrm{m}$.

sections, although with a weaker signal and a higher background noise.

The selectivity of the VGAT labeling is illustrated by the following immunogold particle densities (particles/ $\mu \mathrm{m}^{2}$, excluding mitochondria; tissue fixative C) observed with the N2 antibody in the cerebellar granule cell layer [mean $\pm \operatorname{SEM}(n)]$ : VGAT-immunoreactive Golgi terminals (i.e., mixed GABA-glycine; Ottersen et al., 1988), $66.9 \pm 12.8$ (83); mossy fiber terminals (i.e., glutamatergic; Ji et al., 1991), $1.7 \pm 0.20$ (40); and granule cell dendritic digits (i.e., postsynaptic), $1.1 \pm 0.25$ (87). The difference between the former and the two latter densities, indicating a low tissue background level, was statistically highly significant ( $p<0.00003$, ANOVA, Newman-Keuls test). Back- ground particle density over empty resin was negligible and was not subtracted. A few terminals with appearance and size like Golgi terminals had low particle densities, similar to those over mossy fiber boutons.

The association of VGAT with synaptic vesicles was studied in the cerebellar basket cell terminals. In these, synaptic vesicles are displaced from parts of the terminals by groups of mitochondria and bundles of filaments, and as indicated by immunoperoxidase results (Figs. 7, 8, 11 $A$ ), VGAT labeling was restricted to the regions of the terminals containing synaptic vesicles (Fig. $11 B-$ $D)$. There was no labeling of the plasma membrane (Figs. 10, 11). Within the vesicle-containing regions, the gold particles appeared more closely associated with the synaptic vesicles than with the

labels the same boutons $\left(T_{b}\right.$, basket) or the same type of boutons ( $T_{d}$, Golgi) as does the antiserum to the $\mathrm{N}$ terminus. Boutons with pleomorphic vesicles $\left(T_{e}\right)$ making symmetric contacts $(E$, inset $)$ on the somata $(S o)$ of hippocampal pyramidal cells are heavily labeled for VGAT. In the cerebellar nuclei and striatum, VGAT labeling is likewise in terminals $\left(T_{f}, T_{g}\right)$, making symmetric synapses. Terminals $\left(T^{\prime}\right.$ in $\left.E, G\right)$ making asymmetric synapses on spines $(S)$ and other structures in the neuropil are not labeled. In the cochlear nuclei, putative glycinergic terminals $\left(T_{h}\right)$ are also labeled for VGAT. $D$, So, Dendrites (or dendritic digits) and somata contacted by VGAT-containing boutons; arrowheads, synaptic membrane specializations. Scale bars: $0.5 \mu$ m; inset, $0.25 \mu \mathrm{m}$. 

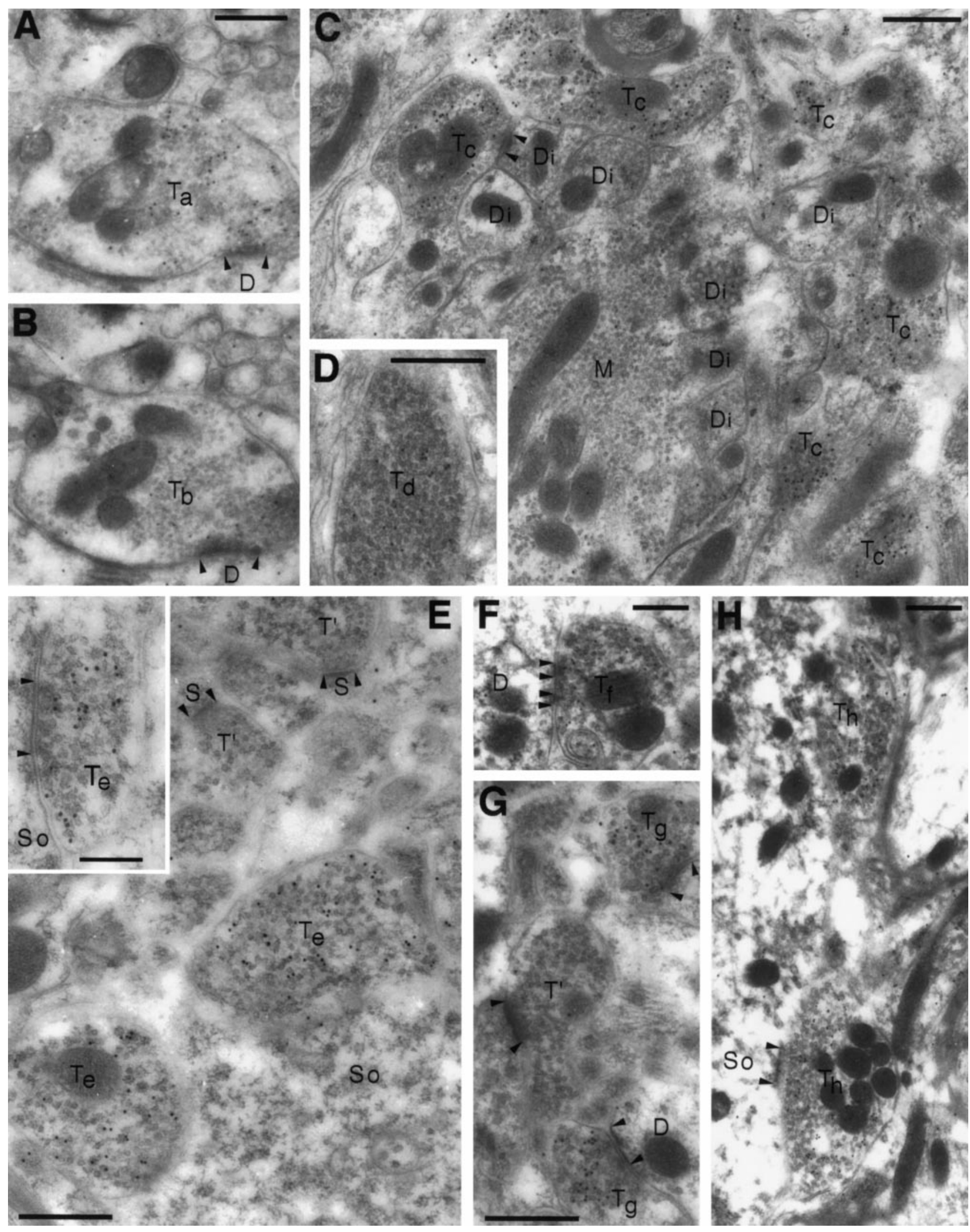

Figure 10. Electron microscopic post-embedding immunogold localization of VGAT illustrated in different brain regions. $A-D$, Cortex cerebelli. $E$, Hippocampus CA1. $F$, Nucleus interpositus (a central cerebellar nucleus). $G$, Caudatoputamen. $H$, Nucleus cochlearis dorsalis. $A$, $C, E-H$, Antiserum N2. $B$, $D$, Antiserum $\mathrm{C} 1$. The antiserum $\mathrm{N} 2$ to the $\mathrm{N}$ terminus of VGAT labels both basket cell boutons $\left(T_{a}\right)$ contacting Purkinje cell dendrites $(D)$ in the molecular layer and Golgi cell boutons $\left(T_{c}\right)$ in the granule cell layer of cerebellum. Only few particles can be detected in mossy fiber terminals $(M)$, granule cell dendritic digits $(D i)$, or other structures in the neuropil. In parallel sections, the antiserum $\mathrm{C} 1$ to the $\mathrm{C}$ terminus (Figure legend continues on preceding page) 
intervening cytoplasmic matrix (Fig. 11D). This was further analyzed in two ways (see Materials and Methods): (1) the correlation of the presence of immunogold particles and synaptic vesicles within squares placed in a lattice over the terminals, excluding mitochondria, was statistically highly significant $(p<$ 0.0001 ); and (2) the intercenter distance between immunogold particles and synaptic vesicles was highly significantly different from that between vesicles and points randomly distributed over the terminals, excluding mitochondria and filament bundles (Fig. 12). Thus $50 \%$ of the particle centers occurred within $20 \mathrm{~nm}$ from the center of the nearest synaptic vesicle, compared with $25 \%$ for random points. Beyond $40 \mathrm{~nm}$, random points were relatively much more frequent than gold particles.

Nerve endings immunopositive for VGAT represent populations of predominantly GABAergic terminals (Fig. 10A,B,E-G), as well as mixed GABAergic-glycinergic (Fig. 10C,D) and predominantly glycinergic terminals (Fig. 10H). The localization of VGAT in glycinergic as well as in GABAergic nerve endings was proven by triple-labeling experiments in LSO. Three consecutive ultrathin sections were immunogold-labeled for GABA, glycine, and VGAT, respectively (Figs. $13 A-C, 14 A-C$ ). Nerve endings rich in GABA and VGAT had varying levels of glycine (Fig. 13, $\left.T_{c}, T_{f}\right)$. On the other hand, terminals containing high levels of glycine (Fig. 13, $\left.T_{b}, T_{d}\right)$ but little $\left(T_{b}\right)$ or no $\left(T_{d}\right)$ GABA were immunopositive for VGAT. The same phenomenon is illustrated in Figure 14 (terminal $T_{b}$ ). Some of the postsynaptic perikarya in LSO are glycine immunoreactive (cf. Ottersen et al., 1995) and showed a slight VGAT signal (Fig. 14).

Quantitative analysis of VGAT-immunoreactive boutons in LSO showed the following immunogold particle densities [particles $/ \mu \mathrm{m}^{2}$ of bouton area excluding mitochondria, mean \pm SEM (n), tissue fixative B]: GABA-immunoreactive terminals (with or without glycine), $23.8 \pm 1.2(29)$; terminals immunoreactive for glycine but not for GABA, $12.7 \pm 0.7$ (24); and adjacent dendrites (indicating the low tissue background level), $1.35 \pm 0.17$ (43). All three items were statistically significantly different from each other ( $p=0.0001$, ANOVA, Newman-Keuls test). For these experiments, three adjacent sections were immunogoldprocessed for GABA, glycine, and VGAT, respectively (as in Figs. 13, 14). The same terminals were identified in all of the three sections. (These particle densities cannot be directly compared with those presented above for cerebellum, because the tissue fixative and the exposure to antibodies differed.) The results suggest that GABAergic nerve endings are equipped with a higher concentration of VGAT than are glycinergic nerve terminals.

The analysis in LSO further revealed that some nerve endings immunopositive for GABA or glycine had low or negligible labeling for VGAT. This is illustrated in Figure 14 for glycinelabeled $\left(T_{a}\right)$ and GABA-labeled $\left(T_{c}\right)$ terminals. In the material investigated, 10 of 39 GABA-immunoreactive terminals (with or without glycine) and 2 of 26 purely glycine-immunoreactive terminals lacked clear VGAT labeling.

\section{DISCUSSION}

\section{Validity of the immunocytochemical labeling}

The recognition by the $\mathrm{N}$-terminal antibody $\mathrm{N} 2$ of a single protein with the expected molecular mass in brain as well as in transfected cells demonstrates the specificity of this antibody. Absorption of the antibody with VGAT fusion protein eliminated the immunoreactivity, further supporting the specificity of N2. Thus, although the existence of a cross-reacting protein with the same electrophoretic migration as VGAT cannot be strictly excluded, the observed labeling of tissue structures by $\mathrm{N} 2$ does represent the presence of VGAT, as far as can be judged without the availability of knock-out animals. (The use of the terms "VGAT immunoreactivity" and "VGAT labeling" imply these reservations.) If a cross-reacting protein should exist, it could be another family member very similar to VGAT. Antibody $\mathrm{C} 1$ to the C-terminal part of VGAT detected a band of the same molecular mass as antibody N2 but also recognized a lower molecular mass band, possibly a proteolytic cleavage product. Consistent with this possibility, although the nature of the latter species remains to be determined, immunocytochemical labeling with the antibody $\mathrm{C} 1$ matches labeling with the N-terminal antibody at regional, cellular (immunoperoxidase), and subcellular (post-embedding immunogold) levels.

\section{Proof that VGAT localizes to synaptic vesicles}

Our electron microscopic observations establish that VGAT is indeed restricted to synaptic vesicles in inhibitory terminals, as was inferred from light microscopic observations (McIntire et al., 1997). First, immunoperoxidase labeling was strongest in the parts of labeled nerve endings that contain large numbers of synaptic vesicles, even when vesicle-poor regions were closer to the surface from which the antibody and other immunoreactants had to diffuse. Second, post-embedding immunogold localization (in which the antibodies have direct access to the antigenic sites exposed at the surface of the ultrathin section) showed immunoreactivity to be confined to the parts of the nerve endings that contain synaptic vesicles. Third, the immunogold labeling was shown to be associated with the vesicles rather than with the intervening cytoplasmic matrix.

The latter is not a trivial task: the maximum distance between an antigenic site and an immunogold particle is of the same order of magnitude as a synaptic vesicle diameter. Thus the centers of immunogold particles occur up to $>45 \mathrm{~nm}$ away from a membrane carrying the antigenic epitope (Chaudhry et al., 1995). On the other hand, because of the fact that the section thickness is similar to the diameter of synaptic vesicles $(20-50 \mathrm{~nm}$; Peters et al., 1991), extravesicular cytoplasm may be projected over a vesicle profile. For the same reason, vesicular antigenic epitopes may be inaccessible to the antibodies, when a vesicle does not reach the surface of the section onto which the antibodies are applied, because antibodies cannot penetrate the plastic to reach antigenic epitopes situated deep in the section. Because of these factors, and because vesicles tend to be closely packed, it is impossible to know whether an individual immunogold particle represents a vesicular antigenic epitope. Statistical methods were therefore applied (Gundersen et al., 1998). These showed (1) that immunogold particles and synaptic vesicles were highly correlated spatially, and (2) that the intercenter distance from an immunogold particle to the nearest synaptic vesicle was more frequently short and less frequently long, compared with points randomly distributed over the vesicle-containing areas of the immunoreactive nerve endings.

Although the membranes of synaptic vesicles must get briefly incorporated into the plasma membrane during exocytosis, VGAT evidently does not attain a high enough concentration in the plasma membrane to be demonstrated by the present method: the plasma membrane of the labeled terminals seemed clear of immunogold particles. 

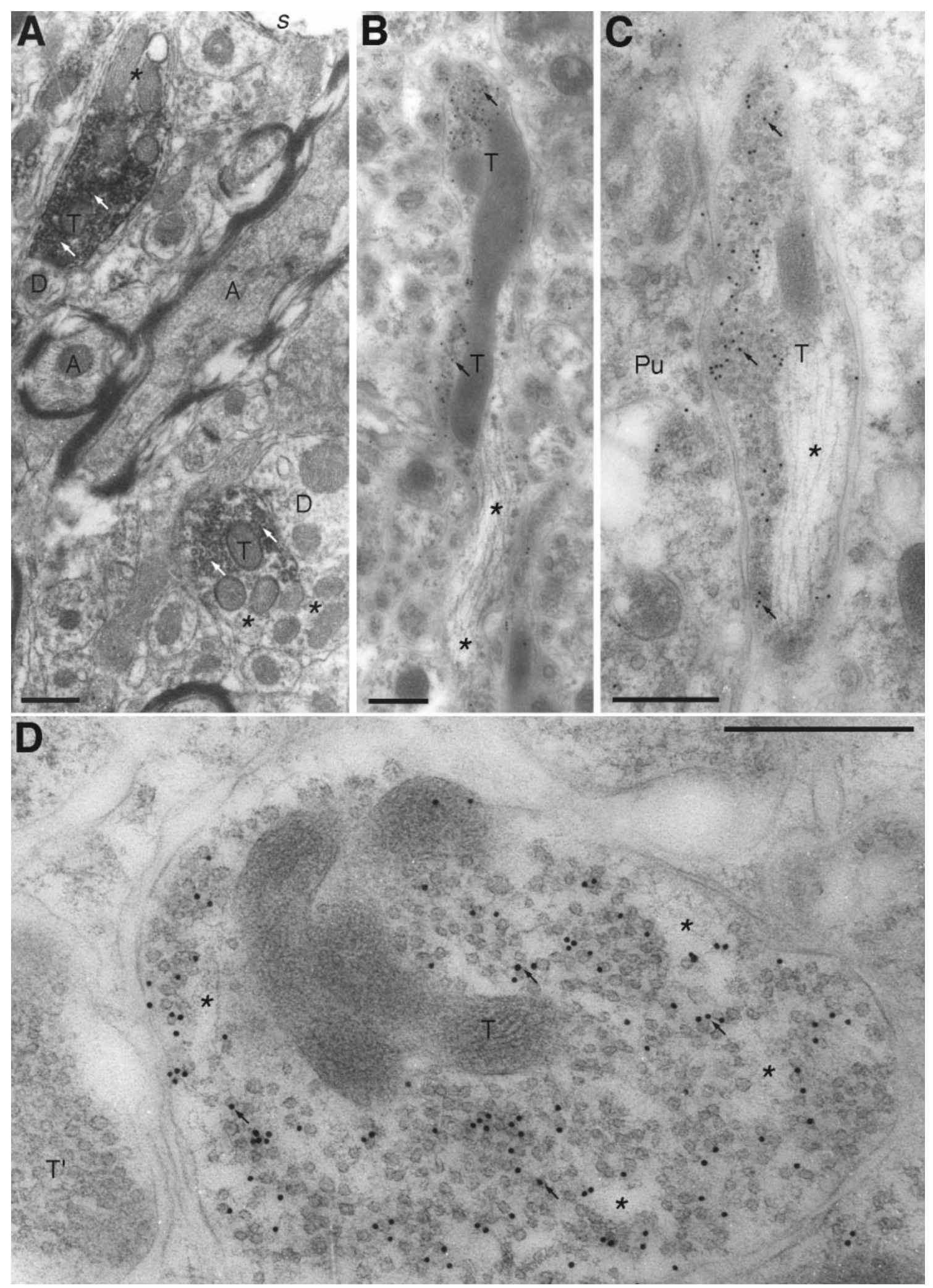

Figure 11. VGAT is associated with synaptic vesicles. $A$, Pre-embedding electron microscopic peroxidase immunocytochemistry suggests VGAT to be confined to the vesicle-rich areas (arrows) of the labeled terminals $(T)$ and absent from the areas devoid of vesicles (stars), even when the latter are closer to the surface $(s)$ of the Vibratome section (cerebellar nucleus with VGAT-containing terminals). $B$, $C$, The vesicular localization is confirmed by post-embedding immunogold labeling. The gold particles are restricted to vesicle-containing areas (arrows), whereas particles are rare in the rest of the terminal, containing neurofilaments (stars), mitochondria, or intervesicular cytoplasmic matrix. Note that at higher power $(D)$, the plasma membrane appears clear of labeling, and that most of the particles are associated with the vesicles (basket cell terminals in cerebellar cortex). T, VGAT-labeled terminals; $T^{\prime}$, VGAT-negative terminal; $D$, dendrites; $A$, myelinated axons; $P u$, Purkinje cell body. Scale bars: $A-C, 0.5 \mu \mathrm{m} ; D, 0.25 \mu \mathrm{m}$. 


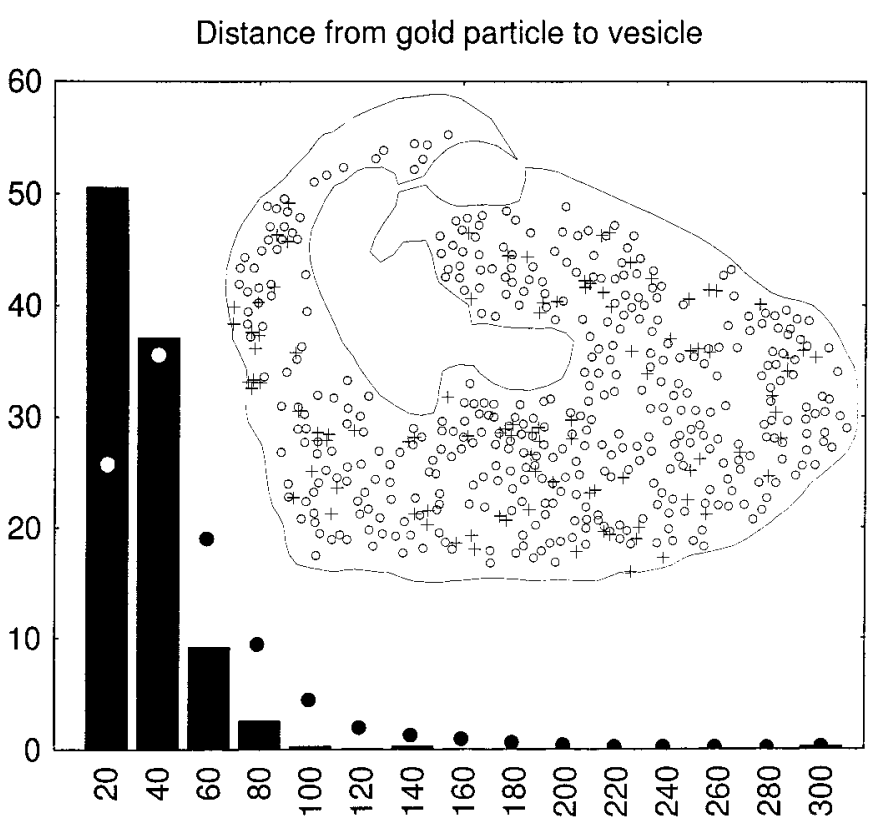

Figure 12. Quantification of the association of VGAT with synaptic vesicles (GABAergic basket cell terminals in the cerebellar cortex). Inset, Illustration of the recording of data, exemplified by the terminal shown as an electron micrograph in Figure $11 D$; the center of each gold particle $(+)$ and of each identifiable synaptic vesicle $(\bigcirc)$ is digitized, as well as the outline of the terminal, excluding mitochondria and (in other terminals) areas occupied by filaments (compare Fig. $11 B, C$ ). Columns, Intercenter distances between each gold particle (394 particles in 12 terminals) and the nearest synaptic vesicle sorted into bins of $20 \mathrm{~nm}$, the $y$-axis showing percent of total in each bin (columns). Filled circles, Distances to the vesicle centers from points ( 1000 per terminal) randomly distributed over the parts of the terminals accessible to synaptic vesicles (see inset). The two distributions were statistically significantly different $(p=0.0005$, continuity corrected $\chi^{2}$ test).

\section{Presence of VGAT in both GABAergic and glycinergic nerve endings}

We demonstrate VGAT immunoreactivity in the terminals of the easily identifiable GABAergic neurons in the CNS. In addition, terminals of glycinergic neurons are labeled, whereas putative glutamatergic nerve terminals show no immunoreactivity. VGAT therefore appears selectively localized in nerve endings releasing, separately or together, the inhibitory amino acids GABA and glycine. This result is consistent with most biochemical data on uptake of GABA and glycine in synaptic vesicles (Christensen et al., 1990, 1991; Burger et al., 1991). The report by Kish et al. (1989) that GABA and glycine did not inhibit the uptake of each other in synaptic vesicle preparations may have resulted from the use of a prolonged incubation time (10 $\mathrm{min})$ and/or low substrate concentrations, perturbing the assay conditions (Christensen et al., 1991). Furthermore, despite the fact that inhibitory nerve endings in the forebrain are not enriched with glycine, the vesicular uptake of glycine is similar in forebrain and spinal cord (Christensen et al., 1991).

While the present study was in progress, a cDNA almost identical to that encoding VGAT was cloned in mouse (Sagné et al., 1997). This transporter was termed "vesicular inhibitory amino acid transporter" (VIAAT), because glycine inhibited $\left[{ }^{3} \mathrm{H}\right] \mathrm{GABA}$ uptake, the cDNA also appeared to induce uptake of $\left[{ }^{3} \mathrm{H}\right]$ glycine ( $<10 \%$ increase over background), and in situ hybridization in rat brain indicated expression of VIAAT mRNA not only in GABAergic neurons but also in regions rich in
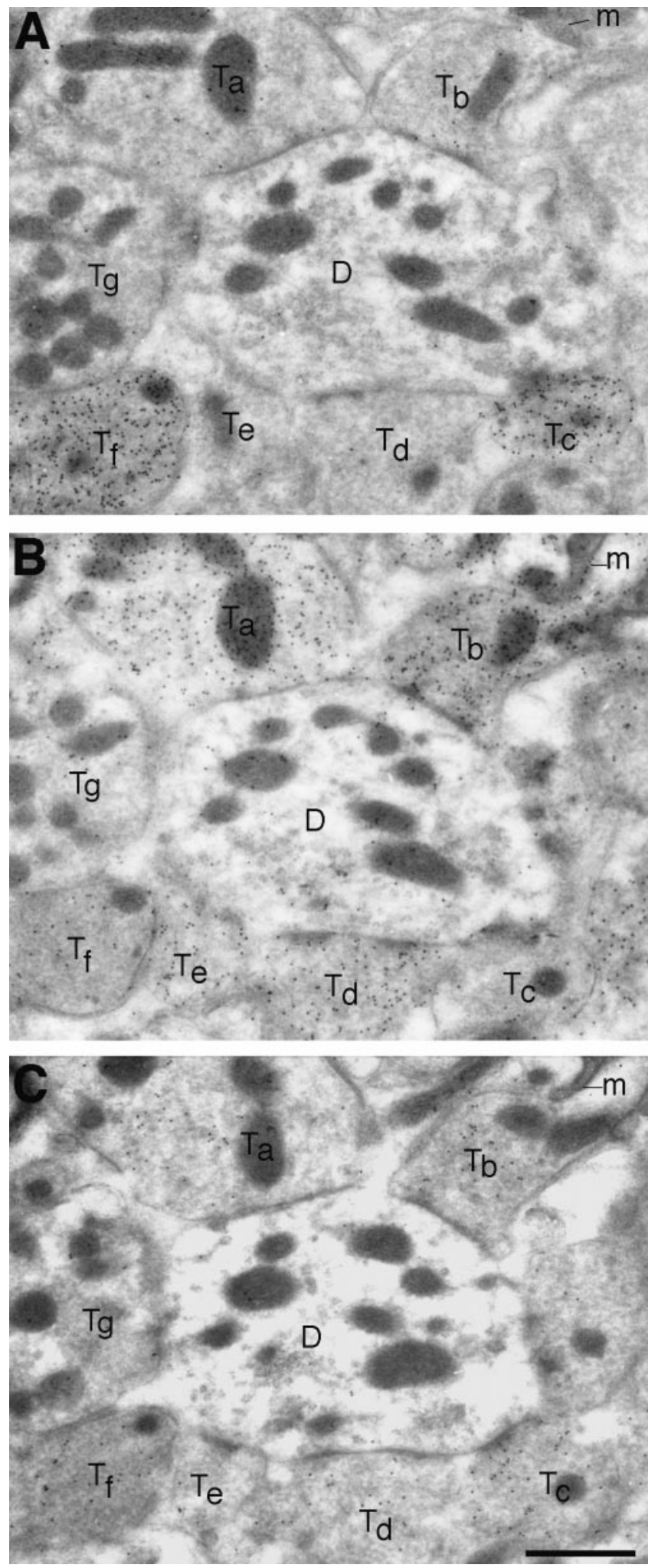

Figure 13. Triple labeling for $\operatorname{GABA}(A)$, glycine $(B)$, and $\operatorname{VGAT}(C)$ in adjacent ultrathin sections of LSO. VGAT is localized in terminals selectively immunoreactive for GABA $\left(T_{c}\right)$, as well as in ones showing mixed immunoreactivity for GABA and glycine $\left(T_{f}\right)$ or selective immunoreactivity for glycine $\left(T_{a}, T_{b}, T_{d}\right)$. One small putative glycinergic terminal $\left(T_{e}\right)$ has only a low (perhaps insignificant) level of VGAT. A putative glutamatergic terminal $\left(T_{g}\right)$ illustrates the low "background" levels of particle densities. The postsynaptic dendrite $(D)$ has a slight glycine signal. $m$, Mitochondria. Scale bar, $1 \mu \mathrm{m}$. 

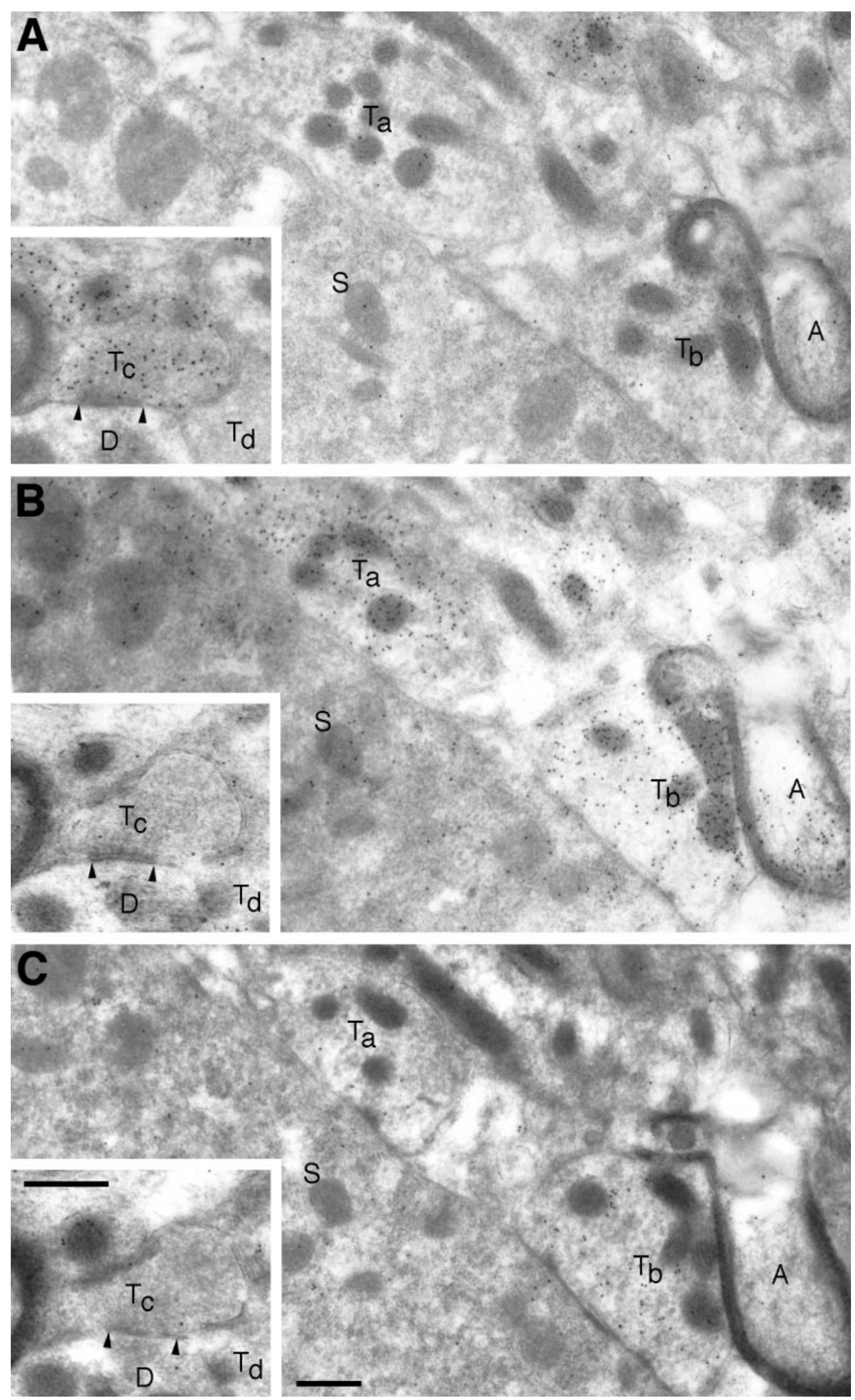

Figure 14. Zero or low levels of VGAT in subpopulations of nerve terminals that are enriched with GABA or glycine. Adjacent ultrathin sections of LSO were incubated with antibodies to GABA $(A)$, glycine $(B)$, and VGAT $(C)$. Two putatively "pure" glycinergic terminals $\left(T_{a}\right.$ and $\left.T_{b}\right)$, synapsing on a neuronal soma $(S)$, show differential VGAT labeling. Although $T_{b}$ is enriched with VGAT, $T_{a}$ is not. In $A$, contrast the lack of GABA immunoreactivity in vesiclecontaining areas of $T_{a}$ and $T_{b}$ with the intense labeling of a nearby small terminal (at the top border). A myelinated axon $(A)$ is immunoreactive for glycine. Insets, A GABA-labeled terminal $\left(T_{c}\right)$, forming a symmetric synapse on a dendrite $(D)$, is not labeled for glycine or for VGAT. Another terminal $\left(T_{d}\right)$ apposed to the same dendrite is unlabeled with all three antibodies. The postsynaptic neuronal soma $(S)$ has a moderate glycine signal and a slight VGAT signal. Scale bars, $0.5 \mu \mathrm{m}$. glycinergic neurons. $\left[{ }^{3} \mathrm{H}\right]$ Glycine uptake by VGAT has since been demonstrated also by E. Giovanetti, R. J. Reimer, and R. H. Edwards (unpublished data). In light of the present results, the difficulties of both groups to demonstrate a robust signal of $\left[{ }^{3} \mathrm{H}\right]$ glycine uptake probably represents a technical problem. However, the possibility still exists that glycine uptake in situ is mediated by an additional protein.
Because GABA and glycine appear to share a vesicular uptake mechanism, they must accumulate in and undergo release from the same synaptic vesicles. The latter has recently been demonstrated in the spinal cord by recording miniature inhibitory postsynaptic currents (Jonas et al., 1998). Other factors, such as transmitter synthesis and plasma membrane uptake, may determine whether synaptic vesicles preferentially accumulate GABA 
or glycine (cf. Christensen et al., 1991). These factors will differ among terminals but should be uniform for the vesicles within a single terminal. At least in the LSO, there appears to be a switch from GABAergic to mainly glycinergic during development (Kotak et al., 1998).

In the absence of GAD, most nerve endings contain virtually no GABA, whereas glycine is present in varying amounts. If the vesicles have VGAT, they will therefore contain glycine but no GABA. In the presence of GAD, the GABA formed will compete with glycine, partly or fully replacing vesicular glycine. Many nerve endings are observed to have both glycine and GABA, both of which appear to associate with synaptic vesicles (Ottersen et al., 1988, 1990). However, experiments with cerebellar slices in vitro suggest that the depolarization-induced depletion of glycine from Golgi terminals is calcium-dependent to a lesser extent than that of GABA (Ottersen et al., 1990), raising the possibility of nonvesicular release. Further experiments will be needed to determine whether this is a general phenomenon, and whether it results from reduced incorporation of glycine relative to GABA into synaptic vesicles.

The observation that GABA-rich nerve terminals in LSO contain more VGAT than do glycine-rich terminals was surprising. In synaptic vesicles isolated from rat CNS, GABA appears to have a higher affinity than glycine for vesicular uptake, and at $1 \mathrm{~mm}$, GABA accumulates twice as rapidly as glycine, regardless of whether the vesicles come from the brain or spinal cord (Christensen et al., 1991). VGAT or VIAAT expressed in vitro also appear to have a higher affinity for GABA than for glycine (McIntire et al., 1997; Sagné et al., 1997). GABAergic nerve endings may therefore need less VGAT than glycinergic terminals to fill their vesicles with transmitter. Other factors, possibly including prevailing firing patterns, may therefore explain the observed opposite difference.

Glycinergic nerve endings appear to be uniquely equipped with the plasma membrane glycine transporter GLYT2 (Zafra et al., 1995). This transporter may provide a supply of glycine for the incorporation into synaptic vesicles of glycinergic nerve terminals. GLYT2 apparently does not occur in the forebrain; neither do nerve terminals enriched with glycine or functional strychninesensitive glycine receptors (Ottersen and Storm-Mathisen, 1990), although glycine receptor mRNAs do (Malosio et al., 1991). However, because glycine is presumably present at low concentrations in all cells, it is likely that small amounts of glycine accumulate along with GABA in VGAT-containing synaptic vesicles of forebrain GABAergic neurons and could undergo corelease with GABA. If so, this could contribute to the (low) extracellular levels of glycine that are required for activating glutamate receptors of the NMDA type (Johnson and Ascher, 1987).

Despite what has been discussed above, it should be borne in mind that the existence of other, yet unidentified, selective transporters has not been excluded. An indication that such proteins may exist is provided by our finding of nerve endings apparently devoid of VGAT but containing GABA or glycine.

\section{REFERENCES}

Barber R, Saito K (1976) Light microscopic visualization of GAD and GABA-T in immunocytochemical preparations of rodent CNS. In: GABA in nervous system function (Roberts E, Chase TN, Tower DB, eds), pp 113-132. New York: Raven.

Berod A, Hartman BK, Pujol JF (1981) Importance of fixation in immunohistochemistry: use of formaldehyde solutions at variable $\mathrm{pH}$ for the localization of tyrosine hydroxylase. J Histochem Cytochem 29:844-850.
Blackstad TW, Karagülle T, Ottersen OP (1990) MORFOREL, a computer program for two dimensional analysis of micrographs of biological specimens, with emphasis on immunogold preparations. Comput Biol Med 20:15-34.

Burger PM, Hell J, Mehl E, Krasel C, Lottspeich F, Jahn R (1991) GABA and glycine in synaptic vesicles: storage and transport characteristics. Neuron 7:287-293.

Ceranik K, Bender R, Geiger JP, Monyer H, Jonas P, Frotscher M, Lubke J (1997) A novel type of GABAergic interneuron connecting the input and the output regions of the hippocampus. J Neurosci 17:5380-5394.

Chaudhry FA, Lehre KP, Van Lookeren Campagne M, Ottersen OP, Danbolt NC, Storm-Mathisen J (1995) Glutamate transporters in glial plasma membranes: highly differentiated localizations revealed by quantitative ultrastructural immunocytochemistry. Neuron 14:711-720.

Christensen H, Fykse EM, Fonnum F (1990) Uptake of glycin into synaptic vesicles isolated from rat spinal cord. J Neurochem 54:1142-1147.

Christensen H, Fykse EM, Fonnum F (1991) Inhibition of gammaaminobutyrate and glycine uptake into synaptic vesicles. Eur J Pharmacol 207:73-79.

Dehnes Y, Chaudhry FA, Ullensvang K, Lehre KP, Storm-Mathisen J, Danbolt NC (1998) The glutamate transporter EAAT4 in rat cerebellar Purkinje cells: a glutamate-gated chloride channel concentrated near the synapse in parts of the dendritic membrane facing astroglia. J Neurosci 18:3606-3619.

Erickson JD, Eiden LE, Hoffman BJ (1992) Expression cloning of a reserpine-sensitive vesicular monoamine transporter. Proc Natl Acad Sci USA 89:10993-10997.

Erickson JD, Varoqui H, Schafer MK, Modi W, Diebler MF, Weihe E, Rand J, Eiden LE, Bonner TI, Usdin TB (1994) Functional identification of a vesicular acetylcholine transporter and its expression from a "cholinergic" gene locus. J Biol Chem 269:21929-21932.

Fonnum F, Storm-Mathisen J, Walberg F (1970) Glutamate decarboxylase in inhibitory neurons. A study of the enzyme in Purkinje cell axons and boutons in the cat. Brain Res 20:259-275.

Freund TF, Martin KA, Smith AD, Somogyi P (1983) Glutamate decarboxylase-immunoreactive terminals of Golgi-impregnated axoaxonic cells and of presumed basket cells in synaptic contact with pyramidal neurons of the cat's visual cortex. J Comp Neurol 221:263-278.

Frotscher M, Soriano E, Leranth C (1992) Cholinergic and GABAergic neurotransmission in the fascia dentata: electron microscopic immunocytochemical studies in rodents and primates. Epilepsy Res [Suppl] 7:65-78.

Fykse EM, Fonnum F (1988) Uptake of $\gamma$-aminobutyric acid by a synaptic vesicle fraction isolated from rat brain. $\mathrm{J}$ Neurochem 50:1237-1242.

Fykse EM, Fonnum F (1996) Amino acid neurotransmission: dynamics of vesicular uptake. Neurochem Res 21:1053-1060.

Glendenning KK, Masterton RB, Baker BN, Wenthold RJ (1991) Acoustic chiasm. III: Nature, distribution, and sources of afferents to the lateral superior olive in the cat. J Comp Neurol 310:377-400.

Guastella J, Nelson N, Nelson H, Czykzyk L, Keynan S, Miedel MC, Davidson N, Lester HA, Kanner BI (1990) Cloning and expression of a rat brain GABA transporter. Science 249:1303-1306.

Gundersen V, Chaudhry FA, Bjaalie JG, Fonnum F, Ottersen OP, StormMathisen J (1998) Synaptic vesicular localization and exocytosis of L-aspartate in excitatory nerve terminals: a quantitative immunogold analysis in rat hippocampus. J Neurosci 18:6059-6070.

Hálasy K, Somogyi P (1993) Distribution of GABAergic synapses and their targets in the dentate gyrus of rat: a quantitative immunoelectron microscopic analysis. J Hirnforsch 34:299-308.

Hálasy K, Buhl EH, Lorinczi Z, Tamas G, Somogyi P (1996) Synaptic target selectivity and input of GABAergic basket and bistratified interneurons in the CA1 area of the rat hippocampus. Hippocampus 6:306-329.

Helfert RH, Bonneau JM, Wenthold RJ, Altschuler RA (1989) GABA and glycine immunoreactivity in the guinea pig superior olivary complex. Brain Res 501:269-286.

Helfert RH, Juiz JM, Bledsoe Jr SC, Bonneau JM, Wenthold RJ, Altschuler RA (1992) Patterns of glutamate, glycine and GABA immunolabeling in four synaptic terminal classes in the lateral superior olive of the guinea pig. J Comp Neurol 323:305-325.

Hökfelt T, Ljungdahl $\AA$ (1971) Uptake of $\left[{ }^{3} \mathrm{H}\right]$ noradrenaline and 
$\gamma-\left[{ }^{3} \mathrm{H}\right]$ aminobutyric acid in isolated tissues of the rat: an autoradiographic and fluorescence microscopic study. Prog Brain Res 34:87-102.

Hökfelt T, Ljungdahl $\AA$ (1972) Autoradiographic identification of cerebral and cerebellar cortical neurons accumulating labeled gammaaminobutyric acid $\left({ }^{3} \mathrm{H}-\mathrm{GABA}\right)$. Exp Brain Res 14:354-362.

Itouji A, Sakai N, Tanaka C, Saito N (1996) Neuronal and glial localization of two GABA transporters (GAT1 and GAT3) in the rat cerebellum. Brain Res Mol Brain Res 37:309-316.

Ji Z, Aas J-E, Laake J, Walberg F, Ottersen OP (1991) An electron microscopic, immunogold analysis of glutamate and glutamine in terminals of rat spinocerebellar fibers. J Comp Neurol 307:296-310.

Johnson JW, Ascher P (1987) Glycine potentiates the NMDA response in cultured mouse brain neurons. Nature 325:529-531.

Jonas P, Bischofberger J, Sandkuhler J (1998) Corelease of two fast neurotransmitters at a central synapse [see comments]. Science 281:419-424.

Juiz JM, Helfert RH, Bonneau JM, Wenthold RJ, Altschuler RA (1996) Three classes of inhibitory amino acid terminals in the cochlear nucleus of the guinea pig. J Comp Neurol 373:11-26.

Kish PE, Fischer-Bovenkerk C, Ueda T (1989) Active transport of gamma-aminobutyric acid and glycine into synaptic vesicles. Proc Natl Acad Sci USA 86:3877-3881.

Kolston J, Osen KK, Hackney CM, Ottersen OP, Storm-Mathisen J (1992) An atlas of glycine- and GABA-like immunoreactivity and colocalization in the cochlear nuclear complex of the guinea pig. Anat Embryol (Berl) 186:443-465.

Kotak VC, Korada S, Schwartz IR, Sanes DH (1998) A developmental shift from GABAergic to glycinergic transmission in the central auditory system. J Neurosci 18:4646-4655.

Lahjouji F, Barbe A, Chazal G, Bras H (1996) Evidence for colocalization of GABA and glycine in afferents to retrogradely labelled rat abducens motoneurones. Neurosci Lett 206:161-164.

Leergaard TB, Bjaalie JG (1995) Semi-automatic data acquisition for quantitative neuroanatomy. MicroTrace-computer programme for recording of the spatial distribution of neuronal populations. Neurosci Res 22:231-243.

Lehre KP, Levy LM, Ottersen OP, Storm-Mathisen J, Danbolt NC (1995) Differential expression of two glial glutamate transporters in the rat brain: quantitative and immunocytochemical observations. J Neurosci 15:1835-1853.

Liu Y, Edwards RH (1997) The role of vesicular transport proteins in synaptic transmission and neural degeneration. Annu Rev Neurosci 20:125-156.

Liu Y, Peter D, Roghani A, Schuldiner S, Prive GG, Eisenberg D, Brecha N, Edwards RH (1992) A cDNA that suppresses MPP $^{+}$toxicity encodes a vesicular amine transporter. Cell 70:539-551.

Malosio ML, Marqueze-Pouey B, Kuhse J, Betz H (1991) Widespread expression of glycine receptor subunit mRNAs in the adult and developing rat brain. EMBO J 10:2401-2409.

Marcos P, Corio M, Dubourg P, Covenas R, Tramu G (1997) Double immunocytochemistry in pre-embedding electron microscopy for the detection of neurotensin and tyrosine hydroxylase in the guinea pig, using two primary antisera raised in the same species. Brain Res Brain Res Protoc 2:1-8.

Maycox PR, Hell JW, Jahn R (1990) Amino acid neurotransmission: spotlight on synaptic vesicles. Trends Neurosci 13:83-87.

McIntire SL, Reimer RJ, Schuske K, Edwards RH, Jorgensen EM (1997) Identification and chacterization of the vesicular GABA transporter. Nature 389:870-876.

Morara S, Brecha NC, Marcotti W, Provini L, Rosina A (1996) Neuronal and glial localization of the GABA transporter GAT-1 in the cerebellar cortex. NeuroReport 7:2993-2996.

Mugnaini E, Oertel WH (1985) An atlas of the distributionof GABAergic neurons and terminals in the rat CNS as revealed by GAD immunohistochemistry. In: Handbook of chemical neuroanatomy (Björklund A, Hökfelt T, eds), pp 436-608. Amsterdam: Elsevier.

Oertel WH, Schmechel DE, Mugnaini E, Tappaz ML, Kopin IJ (1981) Immunocytochemical localization of glutamate decarboxylase in rat cerebellum with a new antiserum. Neuroscience 6:2715-2735.

Örnung G, Shupliakov O, Ottersen OP, Storm-Mathisen J, Cullheim S (1994) Immunohistochemical evidence for coexistence of glycine and GABA in nerve terminals on cat spinal motoneurons. NeuroReport 5:889-892.

Örnung G, Shupliakov O, Lindå H, Ottersen OP, Storm-Mathisen J, Ulfhake B, Cullheim S (1996) Qualitative and quantitative analysis of glycine- and GABA-immunoreactive nerve terminals on motoneuron cell bodies in the cat spinal cord: a postembedding electron microscopic study. J Comp Neurol 365:413-426.

Örnung G, Ottersen OP, Cullheim S, Ulfhake B (1998) Distribution of glutamate-, glycine- and GABA-immunoreactive nerve terminals on dendrites in the cat spinal motor nucleus. Exp Brain Res 118:517-532.

Osen KK, Ottersen OP, Storm-Mathisen J (1990) Colocalization of glycine-like and GABA-like immunoreactivities. A semiquantitative study in individual neurons in the dorsal cochlear nucleus of cat. In: Glycine neurotransmission (Ottersen OP, Storm-Mathisen J, eds), pp 417-451. Chichester, UK: Wiley.

Ottersen OP (1989) Quantitative electron microscopic immunocytochemistry of amino acids. Anat Embryol (Berl) 180:1-15.

Ottersen OP, Storm-Mathisen J (1984) Neurons containing or accumulating transmitter amino acids. In: Handbook of chemical neuroanatomy, Vol 3 (Björklund A, Hökfelt T, Kuhar MJ, eds), pp 141-246. Amsterdam: Elsevier.

Ottersen OP, Storm-Mathisen J, eds (1990) Glycine neurotransmission. Chichester, UK: Wiley.

Ottersen OP, Storm-Mathisen J, Somogyi P (1988) Colocalization of glycine-like and GABA-like immunoreactivities in Golgi cell terminals in the rat cerebellum: a postembedding light and electron microscopic study. Brain Res 450:342-353.

Ottersen OP, Strom-Mathisen J, Laake JH (1990) Cellular and subcellular localization of glycine studied by quantitative electron microscopic immunocytochemistry. In: Glycine neurotransmission (Ottersen OP, Storm-Mathisen J, eds), pp 303-328. Chichester: Wiley.

Ottersen OP, Hjelle OP, Osen KK, Laake JH (1995) Amino acid transmitters. In: The rat nervous system (Paxinos G, ed), pp 1017-1037. San Diego: Academic.

Palay SL, Chan-Palay V (1974) Cerebellar cortex: cytology and organization. Berlin: Springer.

Paxinos G, Watson C (1986) The rat brain in stereotaxic coordinates. San Diego: Academic.

Peters A, Palay SL, Webster HF (1991) The fine structure of the nervous system: neurons and their supporting cells. New York: Oxford UP.

Radian R, Ottersen OP, Storm-Mathisen J, Castel M, Kanner BI (1990) Immunocytochemical localization of the GABA transporter in rat brain. J Neurosci 10:1319-1330.

Ribak CE, Vaughn JE, Saito K, Barber R, Roberts E (1976) Immunocytochemical localization of glutamate decarboxylase in rat substantia nigra. Brain Res 116:287-298.

Ribak CE, Tong WM, Brecha NC (1996a) Astrocytic processes compensate for the apparent lack of GABA transporters in the axon terminals of cerebellar Purkinje cells. Anat Embryol (Berl) 194:379-390.

Ribak CE, Tong WM, Brecha NC (1996b) GABA plasma membrane transporters, GAT-1 and GAT-3, display different distributions in the rat hippocampus. J Comp Neurol 367:595-606.

Sagné C, El MS, Isambert MF, Hamon M, Henry JP, Giros B, Gasnier B (1997) Cloning of a functional vesicular GABA and glycine transporter by screening of genome databases. FEBS Lett 417:177-183.

Sandler R, Smith AD (1991) Coexistence of GABA and glutamate in mossy fiber terminals of the primate hippocampus: an ultrastructural study. J Comp Neurol 303:177-192.

Schlander M, Thomalske G, Frotscher M (1987) Fine structure of GABAergic neurons and synapses in the human dentate gyrus. Brain Res 185:189-189.

Shupliakov O, Örnung G, Brodin L, Ulfhake B, Ottersen OP, StormMathisen J, Cullheim S (1993) Immunocytochemical localization of amino acid neurotransmitter candidates in the ventral horn of the cat spinal cord: a light microscopic study. Exp Brain Res 96:404-418.

Somogyi P, Takagi H (1982) A note on the use of picric acidparaformaldehyde-glutaraldehyde fixative for correlated light and electron microscopic immunocytochemistry. Neuroscience 7:1779-1783.

Somogyi P, Freund TF, Halasz N, Kisvarday ZF (1981) Selectivity of neuronal $\left[{ }^{3} \mathrm{H}\right] \mathrm{GABA}$ accumulation in the visual cortex as revealed by Golgi staining of the labeled neurons. Brain Res 225:431-436.

Somogyi P, Cowey A, Kisvarday ZF, Freund TF, Szentagothai J (1983a) Retrograde transport of $\gamma$-amino $\left[{ }^{3} \mathrm{H}\right]$ butyric acid reveals specific interlaminar connections in the striate cortex of monkey. Proc Natl Acad Sci USA 80:2385-2389.

Somogyi P, Smith AD, Nunzi MG, Gorio A, Takagi H, Wu JY (1983b) Glutamate decarboxylase immunoreactivity in the hippocampus of the cat: distribution of immunoreactive synaptic terminals with special 
reference to the axon initial segment of pyramidal neurons. J Neurosci $3: 1450-1468$

Somogyi P, Freund TF, Kisvarday ZF (1984) Different types of ${ }^{3} \mathrm{H}-$ GABA accumulating neurons in the visual cortex of the rat. Characterization by combined autoradiography and Golgi impregnation. Exp Brain Res 54:45-56.

Somogyi P, Tamas G, Lujan R, Buhl EH (1998) Salient features of synaptic organisation in the cerebral cortex. Brain Res Brain Res Rev 26:113-135.

Soriano E, Nitsch R, Frotscher M (1990) Axo-axonic chandelier cells in the rat fascia dentata: Golgi-electron microscopy and immunocytochemical studies. J Comp Neurol 293:1-25.

Storm-Mathisen J (1972) Glutamate decarboxylase in the rat hippocampal region after lesions of the afferent fibre systems. Evidence that the enzyme is localized in intrinsic neurones. Brain Res 40:215-235.

Storm-Mathisen J (1975) High affinity uptake of GABA in presumed GABA-ergic nerve endings in rat brain. Brain Res 84:409-427.

Storm-Mathisen J, Fonnum F (1971) Quantitative histochemistry of glutamate decarboxylase in the rat hippocampal region. J Neurochem 18:1105-1111.

Storm-Mathisen J, Leknes AK, Bore A, Vaaland JL, Edminson P, Haug FMS, Ottersen OP (1983) First visualization of glutamate and GABA in neurones by immunocytochemistry. Nature 301:517-520.

Taal W, Holstege JC (1994) GABA and glycine frequently colocalize in terminals on cat spinal motoneurons. NeuroReport 5:2225-2228.

Taxt T, Storm-Mathisen J (1984) Uptake of D-aspartate and L-glutamate in excitatory axon terminals in hippocampus: autoradiographic and biochemical comparison with gamma-aminobutyrate and other amino acids in normal rats and in rats with lesions. Neuroscience 11:79-100.

Todd AJ, Sullivan AC (1990) Light microscope study of the coexistence of GABA-like immunoreactivities in the spinal cord of the rat. J Comp Neurol 296:496-505.

Walberg F, Ottersen OP (1992) Neuroactive amino acids in the area postrema. An immunocytochemical investigation in rat with some observations in cat and monkey (Macaca fascicularis). Anat Embryol (Berl) 185:529-545.

Wenthold RJ, Huie D, Altschuler RA, Reeks KA (1987) Glycine immunoreactivity localized in the cochlear nucleus and superior olivary complex. Neuroscience 22:897-912.

Wentzel PR, De ZC, Holstege JC, Gerrits NM (1993) Colocalization of GABA and glycine in the rabbit oculomotor nucleus. Neurosci Lett 164:25-29.

Yang HW, Min MY, Appenteng K, Batten TF (1997) Glycineimmunoreactive terminals in the rat trigeminal motor nucleus: lightand electron-microscopic analysis of their relationships with motoneurones and with GABA-immunoreactive terminals. Brain Res 749:301-319.

Yoshida M, Tanaka M (1989) Immunohistochemical evidence for convergence of GABA-containing and glycine-containing axon terminals on single spinal motoneurons of the rat. Kurume Med J 36:17-21.

Zafra F, Aragón C, Olivares L, Danbolt NC, Giménez C, Storm-Mathisen J (1995) Glycine transporters are differentially expressed among CNS cells. J Neurosci 15:3952-3969. 